\title{
An Integrative View of the Role of Lachancea thermotolerans in Wine Technology
}

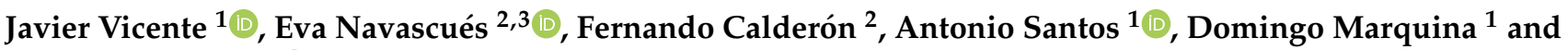 \\ Santiago Benito ${ }^{2, *}$ (1)
}

1 Unit of Microbiology, Genetics, Physiology and Microbiology Department, Biology Faculty, Complutense University of Madrid, Ciudad Universitaria, S/N, 28040 Madrid, Spain; javievic@ucm.es (J.V.); ansantos@ucm.es (A.S.); dommarq@bio.ucm.es (D.M.)

2 Department of Chemistry and Food Technology, Polytechnic University of Madrid, Ciudad Universitaria, S/N, 28040 Madrid, Spain; eva.navascues@upm.es (E.N.); fernando.calderon@upm.es (F.C.)

3 Pago de Carraovejas, Camino de Carraovejas, S/N, 47300 Valladolid, Spain

* Correspondence: santiago.benito@upm.es; Tel.: +34-9133-63710 or +34-9133-63984

Citation: Vicente, J.; Navascués, E. Calderón, F.; Santos, A.; Marquina, D.; Benito, S. An Integrative View of the Role of Lachancea thermotolerans in Wine Technology. Foods 2021, 10, 2878. https://doi.org/10.3390/foods 10112878

Academic Editors: Daniela Fracassett and Laura Rustioni

Received: 13 October 2021

Accepted: 18 November 2021

Published: 21 November 2021

Publisher's Note: MDPI stays neutral with regard to jurisdictional claims in published maps and institutional affiliations.

Copyright: (c) 2021 by the authors. Licensee MDPI, Basel, Switzerland. This article is an open access article distributed under the terms and conditions of the Creative Commons Attribution (CC BY) license (https:// creativecommons.org/licenses/by/ $4.0 /)$

\begin{abstract}
The interest in Lachancea thermotolerans, a yeast species with unusual characteristics, has notably increased in all ecological, evolutionary, and industrial aspects. One of the key characteristics of L. thermotolerans is the production of high quantities of lactic acid compared to other yeast species. Its evolution has mainly been driven by the influence of the environment and domestication, allowing several metabolic traits to arise. The molecular regulation of the fermentative process in L. thermotolerans shows interesting routes that play a complementary or protective role against fermentative stresses. One route that is activated under this condition is involved in the production of lactic acid, presenting a complete system for its production, showing the involvement of several enzymes and transporters. In winemaking, the use of L. thermotolerans is nowadays mostly focused in early-medium-maturity grape varieties, in which over-ripening can produce wines lacking acidity and with high concentrations of ethanol. Recent studies have reported new positive influences on quality apart from lactic acid acidification, such as improvements in color, glutathione production, aroma, malic acid, polysaccharides, or specific enzymatic activities that constitute interesting new criteria for selecting better strains. This positive influence on winemaking has increased the availability of commercial strains during recent years, allowing comparisons among some of those products. Initially, the management of L. thermotolerans was thought to be combined with Saccaharomyces cerevisiae to properly end alcoholic fermentation, but new studies are innovating and reporting combinations with other key enological microorganisms such as Schizosaccharomyces pombe, Oenocous oeni, Lactiplantibacillus plantarum, or other non-Saccharomyces.
\end{abstract}

Keywords: Lachancea thermotolerans; lactic acid; wine; acidity; volatile; evolution; transcriptomic; metabolism regulation; lactate dehydrogenase enzymes

\section{Introduction}

The interest in non-Saccharomyces applications in the wine industry during recent years has increased exponentially, and the number of scientific publications regarding the main species has increased accordingly [1]. Even so, in-depth study of all of the biological aspects surrounding this species has not followed or accompanied this interest. These studies, concerning the metabolic characterization of the species, as well as other evolutional and ecological aspects, may allow a better comprehension of the species and could serve to allow the rational selection of strains and to design new fermentative strategies.

The most studied non-Saccharomyces species are Torulaspora delbrueckii, Lachancea thermotolerans, Schizosaccharomyces pombe, Metschnikowia pulcherrima, Pichia kluyveri and Hanseniaspora uvarum. L. thermotolerans is the most reliable biological option for increasing the acidity and reducing the $\mathrm{pH}$ of wines from warm viticultural areas [2-5]. This is 
because of its unique ability to generate lactic acid from sugar metabolism during alcoholic fermentation [6]. This ability makes $L$. thermotolerans deserving of a section in all reviews dealing with non-Saccharomyces topics in winemaking. Since 2018, when the first review regarding $L$. thermotolerans in the wine industry was written [2], several reports have been published [7-9]. Until now, most reviews have focused on the application of $L$. thermotolerans in wine fermentation, showing some conclusions, establishing possible selection criteria, and proposing further challenges. Other reviews have focused on the beer industry [10]. Nevertheless, the reviews have not related these phenotypic characteristics to their biological basis.

Researchers have made important advances in the elemental biology of L. thermotolerans. The first studies analyzing the diversity among species [11] and the latest study on, not only the intraspecific diversity, but the phylogenetic relationship between them [6], have highlighted low intraspecific diversity. L. thermotolerans inhabits different environments. Among them, enological environments have been highlighted as the best source of isolation [9] due to the large number of strains that have been isolated there. Other environments, such as juices, that present high sugar concentrations are also efficient isolation niches. This agrees with the essential characteristics of $L$. thermotolerans since the species shows an extreme tolerance to high osmotic pressures and can grow in sugar concentrations up to $60 \%(p / p)$ [12]. The influence of these niches of isolation may have a great impact on the evolution of the species [6], influencing intraspecific diversity. Those strains from enological environments seem to be more adapted to those conditions than those from other niches, which directly influences the enological performance of a certain strain [6].

An increase in the number of accessible commercial wine strains has been accompanied by an increase in the scientific interest in L. thermotolerans. In 2018, there was only one available commercial strain of L. thermotolerans [2] sold alone or combined with other non-Saccharomyces strains. Today, there are seven strains from different manufacturers [13]. Two recent studies compare the three most popular available commercial strains [14,15], with an additional study comparing only two of them [16]. However, on some occasions, the results are contradictory, and the performance could depend on additional factors that are different from yeast strain parameters.

In 2018, it was possible to study combinations between L. thermotolerans, S. cerevisiae [2] and S. pombe [17]. Since then, most studies have combined L. thermotolerans with S. cerevisiae in order to ensure proper alcoholic fermentation. These studies allow us to review previous conclusions, test new strains with better performance, and study the influence of the new parameters. A new trend in winemaking is to combine L. thermotolerans with other microorganisms with enological interest. Some articles have studied new parameters, such as mannoproteins and polysaccharides production, in combinations of L. thermotolerans and Schizosaccharomyces pombe [18], achieving the desired microbial stabilization from a malic acid point of view directly after alcoholic fermentation while acidifying wine [19]. Recent works have studied combinations with O. oeni $[15,20]$ in order to achieve microbial stability and to avoid difficult malolactic fermentations under difficult scenarios while acidifying wine. Other studies have investigated multistarters that include L. thermotolerans and other non-Saccharomyces strains such as Torulaspora delbrueckii in order to improve flavor and volatile compound composition [21]. A new combination is a mixed fermentation between L. thermotolerans and Lactiplantibacillus plantarum (formerly Lactibacillus plantarum) [20]. This new biotechnology avoids possible collateral effects produced by the heterofermentative metabolism of $O$. oeni over sugar during long alcoholic fermentations.

Recent studies have explored the influence of $L$. thermotolerans on parameters different from lactic acid acidification but that are still of great interest in modern enology, such as aeration influence [22], glutathione production [23], ethanol reduction [19], sulfur dioxide reduction, [14], polysaccharides production [18], and nitrogen demand.

The aim of the present review is to update the current scientific bibliography regarding L. thermotolerans, review the ecological, evolutional, and molecular information regarding 
this species, compare the commercial offerings, study new fermentation combinations, and synthesize the most important selection parameters.

\section{Genomics, Ecology, and Evolution}

The incongruity of the results regarding the morphology of vegetative cells, sexual states, and the physiological tests to assess a yeast isolate of a certain genus or family has forced the development of other approaches in yeast systematics. In early studies, single-gene sequences were used for a taxonomical assignation, but later, analysis of a combination of multiple-gene sequences was employed. These novel approaches allowed a more accurate methodology to establish the phylogenetic relationships among yeast. Using these approaches, Kurtzman and Robnett [24], analyzing different molecular targets such as 18S rDNA, ITS1-5.8S rDNA-ITS2, 26S rDNA, translation elongation factor $1 \alpha$, actin-1, RNA polymerase II nuclear genes, and cytochrome oxidase II (mitochondrial gene), revealed the presence of different clades among the Saccharomyces complex. One of these clades comprised several yeast species from different genera, separate from the clade that they were supposed to belong to (Clade 10: Zygosaccharomyces cidri, Z. fermentati, Kluyveromyces thermotolerans, and K. waltii). In addition, all of these species were protoploid Saccharomycetaceae, which reveals the divergence of this clade before the whole-genome duplication (WGD) occurred 100-150 million years ago [25]. Further studies have described a new genus that englobes a list of different species, named Lachancea, in honor of Dr. MarcAndré Lachance from Western Ontario University, London, ON, Canada [12]. Nowadays, the genus englobes around 11 different species, $L$. thermotolerans being the type species.

The first genome sequence of the species Lachancea thermotolerans was in 2009 by the Genolevures Consortium [26]. This first genome showed large-scale compositional homogeneity, the GC content variations being linked or limited to local differences between intergenic regions (lower GC content), protein-coding regions (higher GC content), and genes for noncoding RNAs (the highest GC content) [27]. Since then, only two strains have been sequenced for differential lactic acid production [28].

Mitochondrial DNA has been used widely to study genomic evolution within and between different yeast species. Before the Lachancea genus settlement, the study of the restriction patterns of the mitochondrial DNA of several strains of Kluyveromyces thermotolerans showed a high homology among the species, despite the geographic and niche origin of the strains. Originally, this was related to the recent origin of the species, to the action of any evolutionary force, or a low mtDNA substitution rate [11].

Analysis of the mitochondrial genome of different species of the Lachancea genus has revealed syntenic genomes exhibiting a similar architecture. The protein-coding sequences indicate a high level of similarity, in contrast to the significant variation in the size and composition shown by intergenic regions [25]. Already working with Lachancea thermotolerans, this observation was later confirmed to be maintained intraspecifically as well. Freel and co-workers sequenced the mitochondrial genomes of 50 strains from different ecological niches and geographic origins [29]. Mitochondrial genomes have extremely low intraspecific divergence rates $(\pi=0.0014)$, being low in the intergenic sequences and extremely low in the coding regions. Additionally, these genomes have undergone few rearrangements during the evolution of the species. Regarding this information, the different studies have confirmed the hypothesis that this species, as well as the genus, has gone through a strong purifying selection or has an exceptionally low mutation rate as far as the mitochondrial genome is concerned.

Nevertheless, analysis of intraspecific diversity is essential for deepening the understanding of the divergence process that has occurred in a species. Because of the low differentiation of the mitochondrial DNA and the fact that nucleolar genes evolve in different ways and at different rates, these have been the target for determining the evolution process that $L$. thermotolerans has undergone.

The interest in intraspecific diversity, which has a direct influence on the ecological role that a yeast species play in a particular environment, has increased in recent years. 
Since L. thermotolerans is a non-Saccharomyces species with a great impact on and interest in the wine industry, several studies regarding the effects of this intraspecific variation have been carried out.

The first study was carried out by Banilas and co-workers and described the influence of the location in the population structure in strains from different vineyards [30]. A study of several microsatellites dispersed along the nuclear genome of the species in several $L$. thermotolerans strains from two different locations in southern Greece revealed a strong geographical clustering. In each zone, unique molecular patterns were found to be locally conserved; additionally, in each location, the profiles of the strains associated with a certain vineyard were clustered together.

This first study revealed the influence of the location on the species structure; nevertheless, further studies confirmed the influence not only of the location but also of the ecological niche of the isolation [31]. A study of a great number of strains of L. thermotolerans from different niches (natural and anthropic) dispersed along all of the glove revealed several groups clustering according to their ecological origin. Among the identified "natural" or "wild" clusters, the origin of the sample mainly influenced the distribution. What is more, samples with the same origin but collected 20 years apart presented similar genotypes. This result could confirm the domination of a certain genotype in a specific niche, which supports the idea of niche appropriation due to specific metabolic traits and the evolutionary differentiation to specific environmental conditions, as some domesticated strains have revealed [6].

Isolates from anthropic origins show signs of selection, clustering into two separate groups with common ancestors. This reveals the influence of at least two different domestication processes. These strains are not niche-associated, which means that all of the strains come from a single anthropic niche cluster regardless of the source of isolation (wine, milk, agave, fruit, etc.) and geographical origin (e.g., strains from Europe and America cluster together). Sometimes, when there is no limitation between environments, differentiation is not plausible, and the same cluster contains strains from natural and domesticated environments [31].

L. thermotolerans is, in fact, one of the most fermentative yeasts among the nonSaccharomyces group. This feature, a winning trait due to the ability to convert sugars into ethanol under both aerobic and anaerobic conditions, allows it to conquer different niches because of the increased metabolic capacity. L. thermotolerans is among the species that present the Crabtree effect, so under high glucose conditions, this yeast presents aerobic alcoholic fermentation [32]. The metabolic flux under these conditions in this species is still partially unknown, and to clarify this point, carbon metabolism and expression studies are necessary.

Different issues have been studied in order to decipher the role of L. thermotolerans under fermentative conditions, among which the influence of different genetic clusters [6], the transcriptomic/proteomic profiles [33-35], and the molecular basis of such an uncommon activity as lactic acid production $[28,36]$ have been investigated.

Despite L. thermotolerans presenting some signs of domestication and allopatric differentiation, the capacity of proliferation under winemaking conditions may reveal the absence of an important niche specialization process [6]. Different isolates present the same clustering when studying the fermentative profile as previously obtained by microsatellites [31]. Despite this differentiation, the general characteristics seem to be common in the species, regardless of origin, including the low fructophilic character, high fermentation ability, and the production of lactic acid without an increase in acetic acid. Other features indicate the distinct phenotypic performance and are extremely variable among strains, the production of volatile compounds being the most remarkable one.

\section{Molecular Regulation of Fermentation}

Despite the behavior of the species under different conditions and the intraspecific diversity, the analysis of the mechanisms that allow the development of yeast under real 
fermentative conditions is essential to properly know the influence of this species both in the fermentative process and on other species. Figure 1 summarizes the main metabolic routes under fermentative conditions.

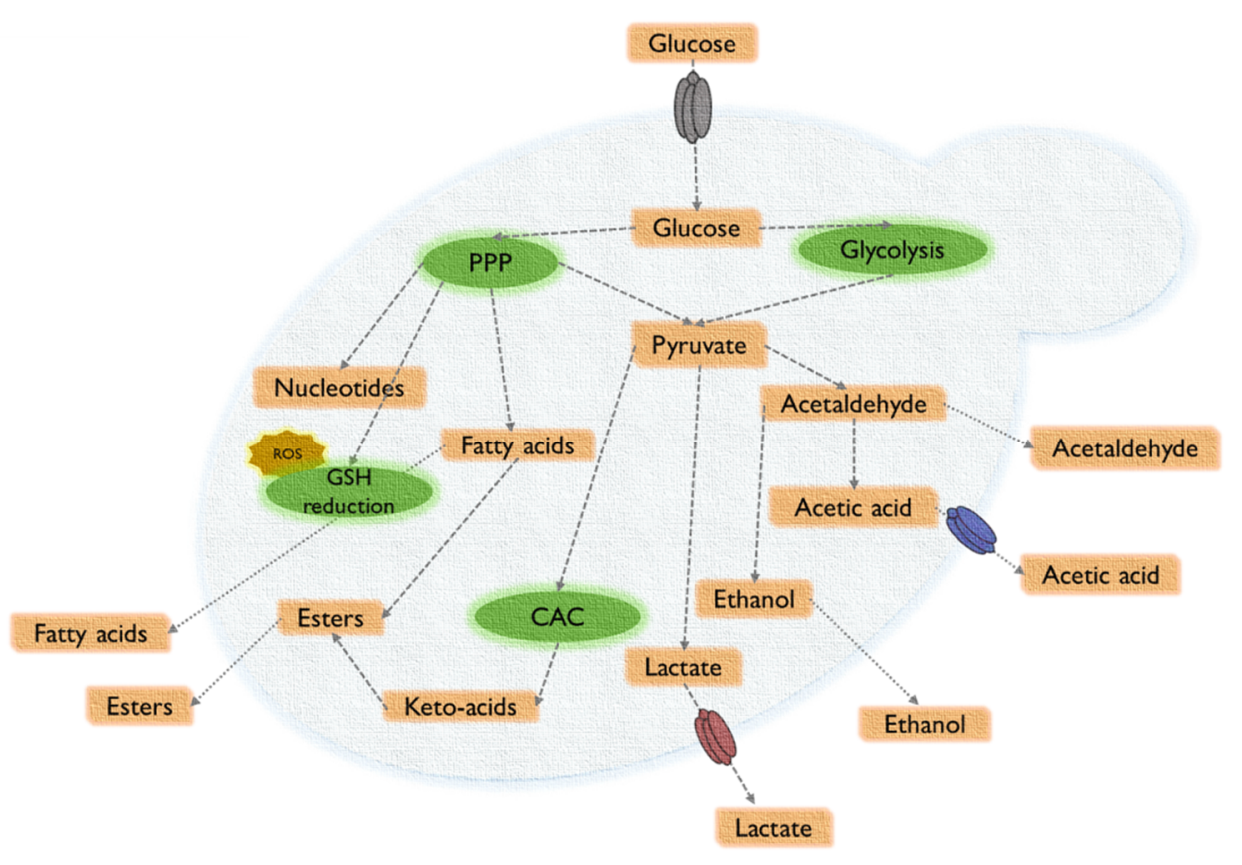

Figure 1. Main metabolic routes in L. thermotolerans under fermentative conditions. Metabolic processes are indicated in green, while intermediate or final metabolites are indicated in yellow. The presence of specific transporters is indicated in the scheme. PPP: Pentose Phosphate Pathway. GSH: Glutathione. ROS: Reactive Oxygen Species (Oxidative stress) CAC: Citric Acid Cycle. Source: self-made.

Alcoholic fermentation, which transforms grape must into wine, is not a single-species process. In most cases, a strong fermentative yeast such as S. cerevisiae is essential to complete the process. The molecular basis of the influence of $L$. thermotolerans on $S$. cerevisiae is essential for understanding how fermentation progresses. The proteomic profile of $S$. cerevisiae under co-fermentation with $L$. thermotolerans shows different signs of stress under the presence of $L$. thermotolerans, displayed with several fighting and defensive mechanisms to keep itself dominant in the first stages of fermentation. As fermentation progresses and the $L$. thermotolerans population decreases, S. cerevisiae increases its enzymatic activity to allow better survival [33]. In the first stages, $S$. cerevisiae increases the nutrient availability and uptake by synthesizing specific proteins that allow the consumption of secondary carbon and nitrogen sources (e.g., aminomethyltransferases for glycine exploitation), as well as others for stress resistance (e.g., heat shock proteins and methionine), and apoptosis repression. On the contrary, in advanced stages of fermentation, L. thermotolerans cells induce protein synthesis (mainly those involved in translation, ribosome biogenesis, and aminoacyl-tRNA synthetases) and repress the stress response [33].

Wine fermentation is an oxygen-limited process in which yeasts may suffer from hypoxic conditions and ethanol or osmotic stresses. L. thermotolerans seems to be more affected by low oxygen availability than by the other conditions. Shekhawat and co-workers analyzed the RNA-seq profile of yeast under oxygen deprivation in order to explain the mechanisms by which the yeast faces this stress, both in pure and mixed fermentations [35].

In single cultures under anaerobic conditions, the main upregulated genes in L. thermotolerans are those involved in glycolysis and fermentation; on the contrary, those genes involved in the pentose phosphate pathway and the citric acid cycle, as well as the main biosynthetic routes (i.e., amino acids and nucleosides synthesis), are downregulated [35]. Among the genes involved in glycolysis and fermentation are those that codify osmotic sen- 
sors, transporters, and the main involved enzymes. Nevertheless, a group of three genes, coding for different lactate dehydrogenases (LDHs), are among the most upregulated and allow one of the most valuable technological applications of L. thermotolerans in wine fermentation - the production of lactic acid. The high expression (as well as its codification) has been linked to a lack in the expression of alcohol dehydrogenase enzymes (only two are expressed in comparison to other yeasts that express up to seven) and to be an alternative pathway to obtain reductive power and to maintain the redox balance. The fermentative process, in combination with oxygen depletion, influences other processes. The main influenced processes are those involved in restoring the damage caused by ethanol: lipid metabolism, cell wall modification, and intracellular homeostasis (ions, oxidative stress, etc.), as well as those involved in autophagy when cells are extremely damaged [35].

In mixed fermentations, anaerobic conditions force L. thermotolerans to exhibit a stronger modification in its expression profile than that displayed by S. cerevisiae [34]. This change in culture conditions has a significant influence on the carbohydrate metabolism and lipid biosynthesis in L. thermotolerans. On the contrary, under anaerobic conditions, when comparing axenic to mixed cultures, the most enriched processes are those related to nutrient uptake, mainly filamentous growth (as a response to starvation) and iron homeostasis. Nevertheless, under these conditions, the most influenced cellular component is the cellular wall upon activating genes for biogenesis and stabilization by $\beta$-glucan synthesis. Taken together, the interaction between mixing and anoxia triggers a strong response in L. thermotolerans, showing increased signals of cell aggregation, cell death, and osmotic and oxidative stresses. The stress to which cells are exposed alters the main carbon metabolism in L. thermotolerans by its redirection to PPP from glycolysis as a possible tool for oxidative stress protection [37]. All genes related to the phenylalanine metabolism and phenylethanol are upregulated, which is in agreement with previous studies regarding the compositional analysis of must, showing that under mixing conditions, the production of phenylethanol is increased compared to single fermentations using $L$. thermotolerans $[2,19]$.

The fermentative conditions force several mechanisms in the sugar metabolism, the most remarkable of which is the increased activity of LDH enzymes, as described before. Despite the production of lactic acid being a general characteristic of the species, the amount produced is extremely variable. The lactic acid metabolism in L. thermotolerans, as well as its real (ecological and evolutionary) relevance, is far from being understood because of the lack of molecular information and prospective studies based in a major universe. Nevertheless, different conditions that may cause a differential production of lactic acid among strains have been studied, including the number and sequence of coding genes for $\mathrm{LDH}$, transcriptional regulation of the enzyme synthesis, and extracellular transport of lactate.

In silico analysis has presented three different LDH coding genes in L. thermotolerans. One of them, designated as $l d h 1$, is located in chromosome D, while the two others, $l d h 2$ and $l d h 3$, are in tandem in chromosome G. Expression analysis of these three genes under fermentative conditions by RT-qPCR has shown that, apparently, only one of them (ldh2) is responsible for the different lactic acid production between strains, with $l d h 1$ and ldh3 showing similar expression profiles in all strains independently of their lactic acid production under fermentative conditions. Interestingly, this increased lactic acid activity is not accompanied by a decreased expression of alcohol dehydrogenase (ADH) genes [36]. A deeper study of the coding regions of the enzymes, including their promoter sequences, showed important differences between high and low lactic acid-producing strains [28]. Gatto and co-workers showed that despite the differences in the aminoacidic sequence between the three enzymes, the key sites in the proteins might not be affected. Phylogenetic analysis of the promoters showed some single-nucleotide mutations (in the TATA box) among strains, which can seriously affect the promoter activity. Among the enzymes, ldh1 and ldh2 presented more similar upstream regions despite the studied strain, whereas ldh2 and ldh3 presented a similar promoter core sequence linked to increased activity. The study of transcription binding factors, which are usually linked to environmental stress responses, 
in the three enzymes showed a specific profile for ldh2 linked to increased activity. The expression of ldh 1 and ldh 2 during the fermentation process presented a similar profile, being more active in the early stages of fermentation, and presenting decreased activity at the end. In high-producing strains, the activity of both enzymes was higher; nevertheless, the differences in the expression of ldh2 were extremely marked. Interestingly, at the end of the fermentation process, both enzymes showed a higher expression level in the low-producing strains.

Changes in the regulatory machinery may allow a better transcriptional rate of the LDH coding genes that, combined with the differential expression, is linked to major activity. Despite this, it is still unknown if the expression differences in these genes are associated with functional ones.

The third element that may play an important role in lactic acid metabolism may be the presence of transporters in charge of its extrusion to the extracellular environment. If a huge amount of lactic acid is accumulated inside cells, it can cause feedback inhibition of the LDH enzyme; thus, transporters for monocarboxylic acids across the membrane are essential for lactic acid production [38-40]. In the case of $L$. thermotolerans, no lactic acid transporter has been confirmed; nevertheless, there are some candidates based on its homology to lactate permeases encoding genes in S. cerevisiae, jen1, and ady2 [28]. Both genes are present in all studied strains, jen 1 being a single copy and $a d y 2$ twice encoded in all strains despite their lactic acid production. It remains unknown if the presence of two copies of the same gene is linked to increased activity since the type of strain, $L$. thermotolerans CBS 6340, which is a low lactic acid producer, presents only one copy of each of these homologs. In engineered S. cerevisiae strains, the increased number of copies or expression levels is not related to a higher lactic acid production [40]. Gatto and co-workers also analyzed the aminoacidic sequence of both transporters, and in the case of jen1, it is more similar in those strains that exhibit a lower production of lactic acid to those that present a higher one. The presence of these two genes confirms the presence of a complete lactate production system.

\section{Impact of L. thermotolerans on Different Wine Quality Parameters}

\subsection{Ethanol}

Modern winemaking is looking for new technologies that are able to reduce the final ethanol concentration of wines from warm viticulture areas. The first studies regarding L. thermotolerans focused on the ability to ferment as much as possible so as not to have a big dependency on the most fermentative yeast species, such as S. cerevisiae [19]. The fermentative power of $L$. thermotolerans varies from $4.24 \%$ to $10.6 \%(v / v)$ depending on the strain $[2,6,41]$ (Table 1$)$. New studies have reported that, depending on the strain variability and physicochemical conditions, L. thermotolerans can ferment up to $13.6 \%(v / v)$ (Table 1$)$, with an ethanol yield from 0.34 to $0.4 \mathrm{~g} / \mathrm{g}$ and generating lactic acid concentrations that vary from 1.8 to $12 \mathrm{~g} / \mathrm{L}$ with an average value of $5.8 \mathrm{~g} / \mathrm{L}$ [6]. These results suggest that with proper management, in the near future, specific $L$. thermotolerans strains could complete alcoholic fermentation in regular wines by themselves without help from other, more fermentative yeasts. 
Table 1. Summary of the variability reported for L. thermotolerans for several wine fermentation quality parameters.

\begin{tabular}{|c|c|c|c|c|c|c|c|c|}
\hline Parameter & $\begin{array}{c}\text { Benito et al., } 2018 \\
{[2]}\end{array}$ & $\begin{array}{l}\text { Hranilovic et al., } \\
2018[6]\end{array}$ & $\begin{array}{c}\text { Binati et al., } 2019 \\
\text { [41] }\end{array}$ & $\begin{array}{c}\text { Binati et al., } 2020 \\
{[42]}\end{array}$ & $\begin{array}{c}\text { Vaquero et al., } 2020 \\
{[16]}\end{array}$ & $\begin{array}{l}\text { Hranilovic et al., } \\
2021 \text { [14] }\end{array}$ & $\begin{array}{c}\text { Zhang et al., } 2021 \\
{[43]}\end{array}$ & $\begin{array}{c}\text { Snyder et al., } 2021 \\
\text { [15] }\end{array}$ \\
\hline Fermentation modality & Pure & Pure & Pure & Sequential & Pure & Sequential & Sequential & Sequential \\
\hline Ethanol $(\% v / v)$ & $3.98-10.35$ & $7.3-10.6$ & $4.24-6.1$ & $11.76-11.97$ & $4.75-8$ & & $13.36-13.53$ & $12.16-12.55$ \\
\hline Glycerol (g/L) & & $3.9-8$ & $3.97-4.99$ & $4.67-5.30$ & & $9.6-11.6$ & $6.95-8.1$ & $6.4-7.2$ \\
\hline Acetic acid (g/L) & $0.1-0.58$ & $0.06-0.32$ & $0.03-0.23$ & $0.19-0.26$ & & $0.29-0.54$ & $0.24-0.37$ & $<0.1-0.13$ \\
\hline Polysaccharides (mg/L) & $163-260$ & & & & & & & \\
\hline Malic acid degradation (\%) & $10-25$ & $(-7)-25$ & & & & $27-57$ & & \\
\hline Lactic acid production $(\mathrm{g} / \mathrm{L})$ & $0.9-4.2$ & $1.8-12$ & $0.69-6.67$ & $0.53-4.42$ & $0.2-3$ & $1-8.1$ & $1.18-1.49$ & $0.2-6.1$ \\
\hline Pyruvic acid (mg/L) & $20-28.5$ & $13-78$ & & & & $60-170$ & & \\
\hline Succinic acid (mg/L) & $287-438$ & & 403-597 & & & $2700-3900$ & & \\
\hline Acetaldehyde $(\mathrm{mg} / \mathrm{L})$ & & & & & & $11.7-18.7$ & & \\
\hline 1-propanol (mg/L) & $20.5-55.4$ & & & & & $29,002-35,699$ & & \\
\hline Isobutanol (mg/L) & $20.6-31.1$ & & & & & $29,207-45,601$ & & \\
\hline Methionol (mg/L) & $0.67-2.6$ & & & & & & & \\
\hline Ethyl acetate $(\mathrm{mg} / \mathrm{L})$ & $31-51$ & & & & & $40,224-79,191$ & $81,197-12,4867$ & \\
\hline Ethyl lactate (mg/L) & $5.5-23.2$ & & & & & $10,617-185,507$ & & \\
\hline Acetoin $(\mathrm{mg} / \mathrm{L})$ & $4.6-108$ & & & & & & & \\
\hline Isovaleric acid (mg/L) & $0.9-2$ & & & & & & & \\
\hline Higher alcohols & & & & & $180-275$ & $430,882-595,281$ & $342,891-400,396$ & \\
\hline
\end{tabular}


An interesting approach of $L$. thermotolerans includes the ability to generate wines with a lower final ethanol concentration in warm viticulture areas for combined fermentations compared to $S$. cerevisiae pure fermentations [19]. Several authors have recommended using $L$. thermotolerans in grape juices that suffer from a lack of acidity and a high potential final ethanol because of high sugar concentrations. L. thermotolerans is less efficient than $S$. cerevisiae, decreasing the ethanol concentration in a range from $0.1 \%$ to $1.6 \%(v / v)[36,44]$. Higher decreases, down to $3 \%(v / v)$ less, take place in combined fermentations with $S$. pombe [45].

The fact that $L$. thermotolerans presents a weaker Crabtree effect than $S$. cerevisiae primarily explains ethanol reduction, which favors the respiratory metabolism. Under fermentative conditions, the other important factors in L. thermotolerans are the production of lactic acid, yeast biomass, glycerol, and pyruvic acid.

\subsection{Glycerol}

Previous studies have typically reported mixed fermentations between L. thermotolerans and S. cerevisiae to be higher in glycerol than the S. cerevisiae control [2]. Such differences are moderate, varying from 0.29 to $0.93 \mathrm{~g} / \mathrm{L}$. The difference between strains is approximately 50\% for 94 strains [6] and 20\% for 13 strains [41], which matches the glycerol yield that varies from 0.02 to $0.047 \mathrm{~g} / \mathrm{g}$ [6].

\subsection{Organic Acids and $p H$}

The lactic acid production is highly variable depending on the conditions and strain used. Previous works have reported maximum levels in lactic acid production between 9.5 and $12 \mathrm{~g} / \mathrm{L}$, which has great importance in $\mathrm{pH}$, reducing it down to 0.59 units [2,15] [6]. Despite these data, some studies have reported strains that produce only approximately $0.69 \mathrm{~g} / \mathrm{L}[2,41,46]$. A previous study reported a lactate yield varying from 0.0086 to $0.0658 \mathrm{~g} / \mathrm{g}$. The achieved acidifications and $\mathrm{pH}$ reductions related to the use of L. thermotolerans are a serious alternative to other acidification technologies such as potassium ion reduction, synthesized acid addition, or early harvest.

The consumption of malic acid by L. thermotolerans may reduce its concentration from $10 \%$ to $50 \%[2,14,47]$. This feature may affect malolactic fermentation, making it shorter, which winemakers appreciate because of the reduction in time and risks. Contrarily, only one study has reported an L. thermotolerans strain (LL12_056) able to increase the malic acid concentration from an initial grape juice of the Chardonnay grape variety, from 3.8 to $4.1 \mathrm{~g} / \mathrm{L}$ of malic acid, although other studied strains have been shown to consume original malic acid down to $3 \mathrm{~g} / \mathrm{L}$ [6]. These results suggest that a few L. thermotolerans strains could possess the ability to generate small amounts of malic acid similar to $S$. cerevisiae species [48]. This ability could be of interest, especially in white wine production, as most commercial white wines do not need malic acid stabilization and could increase the acidification effect of $L$. thermotolerans lactic acid.

L. thermotolerans may produce succinic acid in high concentrations, with an average value among 13 strains of $0.5 \mathrm{~g} / \mathrm{L}$, compared to no succinic acid production in the $S$. cerevisiae control [41]. Contrarily, another study reported succinic acid varies from 13 to $78 \mathrm{mg} / \mathrm{L}[6]$.

\subsection{Acetic Acid}

Previous studies have reported that $L$. thermotolerans produces low concentrations of acetic acid, below $0.24 \mathrm{~g} / \mathrm{L}$, but with a high strain variability of up to $50 \%$ with variations from 0.03 to $0.58 \mathrm{~g} / \mathrm{L}[2,6,41]$. The acetate yield may vary from 0.3 to $1.53 \mathrm{mg} / \mathrm{g}$ [6].

\subsection{Acetaldehyde}

Previous studies have reported L. thermotolerans as a lower producer of acetaldehyde than S. cerevisiae, producing final acetaldehyde concentrations that vary from 15 to $19 \mathrm{mg} / \mathrm{L}$ in pure fermentations [2]. Sequential fermentations usually also show lower final con- 
centrations than pure $S$. cerevisiae controls. However, one scientific article reported the opposite effect for sequential fermentations [2]. A new study that performed five sequential fermentations between different $L$. thermotolerans strains and one $S$. cerevisiae strain reported that all sequential fermentations showed significant differences compared to the $S$. cerevisiae control [14], as well as in other cases [49]. In other cases, two strains of L. thermotolerans reduced the acetaldehyde concentration by 17 and $12 \mathrm{mg} / \mathrm{L}$ compared to the $S$. cerevisiae control. However, one strain did not show significant differences [42].

\subsection{Anthocyanins, Polyphenols, and Color}

The increase in red colorations of anthocyanins takes place when the $\mathrm{pH}$ decreases because lactic acid formation improves the color intensity [19]. The increases in color intensity and total anthocyanins related to the influence of L. thermotolerans vary from $8 \%$ to $10 \%$ [2]. However, sometimes, the color intensity diminishes, probably because of the high strain variability in anthocyanin absorption for this parameter, similar to what occurs for S. cerevisiae [19]. A new study performed in the Sangiovese red grape variety showed that a sequential fermentation between $L$. thermotolerans and S. cerevisiae has a $14 \%$ higher concentration in final total anthocyanins and 9\% more in total polyphenols than the S. cerevisiae control [49]. The same study observed significant differences in color perception, where sequential fermentation of $L$. thermotolerans scored 1.5 , and the S. cerevisiae control scored 1.25, which represents an increase of $16 \%$. Other studies have reported a lower increase of around $12 \%$ when comparing a sequential fermentation involving $L$. thermotolerans and the S. cerevisiae control [20].

\subsection{Glutathione}

Glutathione possesses anti-oxidative properties that are interesting in modern winemaking for avoiding detrimental changes in color and oxidative aromas. It also allows a reduction in the addition of sulfur dioxide, which is a hazardous compound, especially for specific groups at risk, such as people who suffer from asthma, and its legal limits have decreased in recent years [50]. Some non-Saccharomyces strains have been recently reported to be powerful producers of glutathione [23]. Three strains of L. thermotolerans contain glutathione in concentrations varying from 0.205 to $0.537 \mathrm{nmol} / \mathrm{mg}$ cell, while the S. cerevisiae control shows $0.095 \mathrm{nmol} / \mathrm{mg}$ cell. L. thermotolerans produces 2-5 times more glutathione than $S$. cerevisiae. Nevertheless, the strain variability in glutathione production is $60 \%$. For this reason, the production of glutathione may be an interesting selection parameter for future selection processes regarding L. thermotolerans strains.

\subsection{Polysaccharides}

L. thermotolerans has been reported to be a higher producer of polysaccharides than $S$. cerevisiae by up to $23 \%$, but with a high strain variability of up to $60 \%$ [2,49]. Recent studies focused on this parameter have reported $S$. cerevisiae wines without differences between the sequential fermentation and the S. cerevisiae control [18]. It is interesting to mention that among the sequential fermentations of seven different non-Saccharomyces and S. cerevisiae, L. thermotolerans was the highest producer of total polysaccharides. These results show the importance of introducing this parameter in selection processes.

\subsection{Enzymatic Activity}

The enzymatic profile of $L$. thermotolerans is extremely variable [51]. All assayed strains have been shown to be positive for esterase-lipase and leucine-A, while esterase, lipase, valine, cysteine-A, and $\beta$-glucosidase are strain-dependent. Other activities, such as protease, polygalacturonase, glucanase, xylanase, and cellulase, are rare in L. thermotolerans [51,52]. This high strain variability in specific enzymatic activities is of great interest in the L. thermotolerans strain selection processes as well. 


\subsection{Aroma Composition}

L. thermotolerans usually produces wines with lower amounts of total higher alcohols; however, the opposite can take place due to a high strain variability of approximately $40 \%[2,14,44]$ and the aeration conditions of the fermentation [22]. All previous works have reported fermentations involving $L$. thermotolerans to produce higher concentrations of total esters (ethyl and acetate esters) than S. cerevisiae controls, mainly because of ethyl lactate $[14,22,53]$. Compounds such as fatty acid and terpenes are less studied. Under aeration conditions, the fatty acid content may increase [22]; otherwise, it seems to decrease [14]. As far as terpenes are concerned, $L$. thermotolerans does not influence [14,53]or even increases [43] - the final concentration.

\section{L. thermotolerans Commercial Strains Comparisons}

Nowadays, the market offers seven different $L$. thermotolerans strains from three manufacturers $[13,54]$. Additionally, there is a commercial product named Melody ${ }^{\mathrm{TM}}$ (Hansen, Horsholm, Denmark) that consists of a multistarter of three different yeast species, one of them being the L. thermotolerans Concerto strain.

Recent studies have compared some of the different available commercial strains (Levulia $^{\mathrm{TM}}, \mathrm{AEB}$, Italy; Concerto ${ }^{\mathrm{TM}}, \mathrm{CHR}$ Hansen, Denmark; Laktia ${ }^{\mathrm{TM}}$, Lallemand, Canada) [14-16], showing interesting differences and even contradictory results regarding several enological parameters, depending on the study. According to all of them, sequential fermentation using L. thermotolerans and S. cerevisiae is more efficient than co-inoculation as far as lactic acid production is concerned. After studying the comparisons between commercial strains of $L$. thermotolerans fermenting in sequential fermentations, contradictory results have appeared. Such results could show that the commercial strains might perform differently depending on different factors, such as available nutrients, aeration conditions, or other unknown factors. Table 2 summarizes the observed parameters in the studies that have compared commercial L. thermotolerans strains.

Table 2. Summary of studies that have compared different commercial L. thermotolerans strains in wine fermentation.

\begin{tabular}{|c|c|c|c|c|c|}
\hline & & S. cerevisiae & Levulia $^{\mathrm{TM}}$ AEB & Concerto $^{\mathrm{TM}}$ Hansen & Laktia $^{\mathrm{TM}}$ Lallemand \\
\hline \multirow{3}{*}{$\begin{array}{l}\text { Ethanol } \\
\%(v / v)\end{array}$} & Hranilovic et al., 2021 [14] & 16.5 & 16.2 & 15.6 & 15.7 \\
\hline & Snyder et al., 2021 [15] & 12.71 & 12.38 & 12.55 & 12.24 \\
\hline & Vaquero et al., 2020 [16] & 10.2 & n.d.a. & 8 & 6.2 \\
\hline \multirow{3}{*}{$\begin{array}{l}\text { Lactic acid } \\
\quad(\mathrm{g} / \mathrm{L})\end{array}$} & Hranilovic et al., 2021 [14] & 0.4 & 1 & 3.4 & 5.8 \\
\hline & Snyder et al., 2021 [15] & 0.1 & 2.8 & 0.5 & 1.5 \\
\hline & Vaquero et al., 2020 [16] & 0.15 & n.d.a. & $0.15-0.25$ & $0.8-1.8$ \\
\hline \multirow{3}{*}{$\mathrm{pH}$} & Hranilovic et al., 2021 [14] & 3.86 & 3.90 & 3.58 & 3.51 \\
\hline & Snyder et al., 2021 [15] & 3.77 & 3.54 & 3.77 & 3.66 \\
\hline & Vaquero et al., 2020 [16] & 3.7 & n.d.a. & 3.7 & 3.6 \\
\hline \multirow{3}{*}{ Total acidity $(\mathrm{g} / \mathrm{L})$} & Hranilovic et al., 2021 [14] & 5 & 5.1 & 8.1 & 9.1 \\
\hline & Snyder et al., 2021 [15] & 7.1 & 10.4 & 7.1 & 8.7 \\
\hline & Vaquero et al., 2020 [16] & 3 & n.d.a. & 3 & 3.7 \\
\hline \multirow{2}{*}{ Acetic acid (g/L) } & Hranilovic et al., 2021 [14] & 0.15 & 0.47 & 0.49 & 0.45 \\
\hline & Snyder et al., 2021 [15] & 0.17 & $<0.1$ & 0.13 & 0.11 \\
\hline \multirow{2}{*}{$\begin{array}{l}\text { Malic acid } \\
(\mathrm{g} / \mathrm{L})\end{array}$} & Hranilovic et al., 2021 [14] & 2.4 & 1.1 & 1.3 & 1.5 \\
\hline & Snyder et al., 2021 [15] & 4.72 & 4.23 & 4.59 & 4.24 \\
\hline Total SO $\mathrm{S}_{2}(\mathrm{mg} / \mathrm{L})$ & Hranilovic et al., 2021 [14] & 13.3 & 0.5 & 5.9 & 4.8 \\
\hline $\begin{array}{l}\text { Higher } \\
\text { Alcohols } \\
(\mathrm{mg} / \mathrm{L})\end{array}$ & Hranilovic et al., 2021 [14] & 498 & 456 & 595 & 430 \\
\hline $\begin{array}{l}\text { Ethyl esters } \\
(\mathrm{mg} / \mathrm{L})\end{array}$ & Hranilovic et al., 2021 [14] & 40 & 57 & 138 & 163 \\
\hline $\begin{array}{l}\text { Acetate esters } \\
(\mathrm{mg} / \mathrm{L})\end{array}$ & Hranilovic et al., 2021 [14] & 1.73 & 1.80 & 2.65 & 2.11 \\
\hline
\end{tabular}




\subsection{Ethanol}

Using commercial strains may slightly influence the ethanol concentration. Sequential fermentations between the Concerto or Laktia strains and S. cerevisiae achieves ethanol reductions of $0.9 \%(v / v)$ compared to the S. cerevisiae control, while fermentations involving the Levulia strain under these conditions do not show significant statistical differences [14]. All sequential fermentations consume all of the fermentative sugars. Another study reported that the commercial $L$. thermotolerans strains (Laktia, Levulia, and Concerto) slightly reduce the final ethanol concentration in sequential fermentations by $0.475,0.33 \%$, and $0.16 \%(v / v)$, respectively, compared to the S. cerevisiae control [15]. Pure fermentations using Concerto reach an ethanol concentration of up to $8 \%(v / v)$, while Laktia ferments up to $6.2 \%(v / v)[16]$.

\subsection{Glycerol}

The Concerto strain is the highest glycerol producer, up to $11.6 \mathrm{~g} / \mathrm{L}$, while Laktia and Levulia produce slightly lower final concentrations, with non-significant differences between them (both approximately $10 \mathrm{~g} / \mathrm{L}$ ) [14]. The $S$. cerevisiae control produces 30\% less glycerol than the sequential fermentations between Concerto and S. cerevisiae. Other studies have reported non-significant differences for the three studied commercial $L$. thermotolerans strains in sequential fermentations, while the S. cerevisiae control produces $15 \%$ less glycerol [15].

\subsection{Organic Acids and $p H$}

The production of lactic acid, the most valuable virtue of $L$. thermotolerans, is extremely variable depending on the strain and fermentative conditions. The first study that compared three available commercial L. thermotolerans strains (Levulia, Concerto, and Laktia) fermented Merlot grape must via co-inoculation and sequential strategies. Laktia was the highest lactic acid producer, up to $5.8 \mathrm{~g} / \mathrm{L}$ (pH drop of 0.35 units), while Concerto ( $\mathrm{pH}$ drop of 0.15 units) and Levulia produced $41 \%$ and $82 \%$ less, respectively [14]. Another study performed on the Sauvignon blanc grape variety reported sequential fermentations of Levulia to be the highest lactic acid producer, generating up to $2.8 \mathrm{~g} / \mathrm{L}$ and reducing the $\mathrm{pH}$ by approximately 0.23 units, followed by Laktia ( $46 \%$ less and $\mathrm{pH}$ drop of 0.1 units) and Concerto (83\% less) [15]. In other studies, no differences in lactic acid production between Concerto and the $S$. cerevisiae control in pure fermentations using Airen must have been observed, while the use of Laktia allowed to reach up to $1.8 \mathrm{~g} / \mathrm{L}$ of lactic acid [16].

Sequential fermentations involving Levulia and S. cerevisiae have not shown statistical differences to the $S$. cerevisiae control in total acidity, while sequential fermentations involving Concerto and Laktia showed increases of $37 \%$ and $44 \%$, respectively [14]. On the contrary, other cases have not shown differences in the final total acidity concentrations in sequential fermentations involving Concerto and the S. cerevisiae control, while fermentations involving Laktia and Levulia showed higher final concentrations in $18 \%$ and $31 \%$, respectively [15]. In pure Concerto fermentations, compared to the S. cerevisiae control, no difference took place, while the Laktia control increased the total acidity by $0.7 \mathrm{~g} / \mathrm{L}$ in $1 \mathrm{~L}$ fermentations [16].

Similar malic acid degradations of approximately $50 \%$ took place for all of the studied commercial L. thermotolerans strains (Levulia, Concerto, and Laktia) in sequential fermentations with S. cerevisiae, while the S. cerevisiae control degrades $7 \%$ in Merlot wine with an initial malic acid concentration of $2.6 \mathrm{~g} / \mathrm{L}$ [14]. These results are very promising for new strategies trying to generate stable wines from a malic acid point of view directly during alcoholic fermentation, avoiding difficult malolactic fermentations under specific scenarios $[15,19,20]$. However, another study performed in Sauvignon blanc must reported slight reductions of malic acid for the commercial strains that varied from $7 \%$ to $10 \%$, with no differences with the $S$. cerevisiae control; in this case, the initial concentration of malic acid was significantly higher $(4.72 \mathrm{~g} / \mathrm{L})$ [15]. 
No significant differences took place in the final concentration of succinic acid (around $3 \mathrm{~g} / \mathrm{L}$ ) among the commercial strains, although the S. cerevisiae control showed a lower final concentration of approximately $50 \%$. Laktia showed the highest pyruvic acid production, up to $0.17 \mathrm{~g} / \mathrm{L}$, while Concerto and Levulia showed lower concentrations than S. cerevisiae $(0.13 \mathrm{~g} / \mathrm{L})[14]$.

\subsection{Acetic Acid}

L. thermotolerans is generally a lower producer of acetic acid than the Saccharomyces genus [2,7]. However, $L$. thermotolerans possesses a strain variability of up to $50 \%$ in acetic acid production $[2,46]$. Slight differences have been reported in the final concentration of acetic acid for sequential fermentations involving the Laktia, Concerto, and Levulia strains. The acetic acid concentration varied from 0.10 to $0.13 \mathrm{~g} / \mathrm{L}$, while the $S$. cerevisiae control showed significantly higher concentrations that varied from $23 \%$ to $41 \%$ higher than the L. thermotolerans sequential fermentations [15]. Surprisingly, sequential fermentations involving the Levulia L. thermotolerans strain produced $0.29 \mathrm{~g} / \mathrm{L}$ of acetic acid, while Concerto and Laktia fermentations produced $40 \%$ more acetic acid without significant differences between them; the $S$. cerevisiae control produced the lowest final concentration in acetic acid, approximately $50 \%$ less than the Levulia control [14].

\subsection{Total Sulfur Dioxide}

Levulia showed the lowest final concentration in total $\mathrm{SO}_{2}$ of $0.5 \mathrm{mg} / \mathrm{L}$ in sequential fermentations, while the S. cerevisiae control showed a concentration of up to $13.3 \mathrm{mg} / \mathrm{L}$ (96\% higher) [14]. This effect could be related to the low production of acetaldehyde and pyruvic acid in the strain. Concerto and Laktia showed lower values than the $S$. cerevisiae control by $66 \%$ and $74 \%$, respectively. Another study reported that Concerto, Levulia, and Laktia produce lower concentrations of total sulfur dioxide compared to the $S$. cerevisiae control by $65 \%, 61 \%$, and $48 \%$, respectively [15]. The S. cerevisiae control showed a final total sulfur dioxide concentration of $23 \mathrm{mg} / \mathrm{L}$. Although in distinct order, the different studies agree that sequential fermentations involving commercial $L$. thermotolerans strains reduce the final concentration of $\mathrm{SO}_{2}$. This effect is of great interest for the production of wines with low concentrations of $\mathrm{SO}_{2}$ that are highly appreciated by some consumers.

\subsection{Aroma Compounds}

The commercial L. thermotolerans strains (Levulia, Concerto, and Laktia) produced higher concentrations in total esters and lower fatty acids than the S. cerevisiae control [14]. Although all L. thermotolerans strains produced higher total esters than the S. cerevisiae control, there were big differences between them, as Levulia produced $30 \%$ more esters than the S. cerevisiae control, while Concerto and Laktia produced $71 \%$ and $75 \%$ more, respectively [15]. Concerto was the highest producer in sequential fermentations of ethyl acetate, isoamyl acetate, and 2-phenylethyl acetate, while Laktia was the highest producer of ethyl lactate [14]. Another study also observed the commercial L. thermotolerans strains to produce higher concentrations of esters than the S. cerevisiae control, although with bigger differences between Laktia and Concerto [16]. The study reported Laktia to produce, in pure $1 \mathrm{~L}$ fermentations, $40 \%$ more esters than the $S$. cerevisiae control, while Concerto only produced $20 \%$ more. The study highlighted Concerto producing less ethyl acetate than Laktia by approximately $30 \%$.

Levulia produced similar final higher alcohol concentrations to the S. cerevisiae control without significant differences, while Concerto produced $16 \%$ more higher alcohols and Laktia produced $14 \%$ less [14]. Another study reported Laktia and Concerto producing similar final concentrations of higher alcohols in pure fermentations of $1 \mathrm{~L}$, while the $S$. cerevisiae control produced $31 \%$ less [16].

Laktia produced $77 \mathrm{mg} / \mathrm{L}$ of carbonylic compounds, while Concerto produced $39 \%$ less and the $S$. cerevisiae control $61 \%$ less [16]. The only study that reported results regarding fatty acids stated that all commercial $L$. thermotolerans strains produce lower concentrations 
than the S. cerevisiae control [14]. Concerto and Levulia showed similar concentrations of $39 \%$ and $43 \%$ lower than the S. cerevisiae control, while Laktia produced $65 \%$ less.

We can observe that the results are not homogenous regarding aroma compounds depending on the study, which clearly indicates that there could be other significant factors than this strain parameter.

\section{L. thermotolerans Combinations with Other Microorganisms in Wine Technology 6.1. Saccharomyces cerevisiae}

The first study that reported the use of $L$. thermotolerans in winemaking showed that although it is the best biological acidifier, it cannot completely ferment a wine of a regular degree of potential ethanol [55]. The wine reached a final ethanol concentration of $7.58 \%$ $(v / v)$ and the S. cerevisiae control of $9.6 \%(v / v)$. Therefore, the next studies used strains of the Saccharomyces genus as a partner in order to ensure proper alcoholic fermentation [56]. Since then, most studies have employed mixed combinations between $L$. thermotolerans and S. cerevisiae in different modalities, such as mixed initial inoculations with different ratios or sequential fermentations, where L. thermotolerans ferments in the first few hours or days and after Saccharomyces ends its alcoholic fermentation [2]. The sequential modality is the one that allows L. thermotolerans to influence the final chemical composition of wine the most. This is because Saccharomyces usually inhibits the growth of $L$. thermotolerans as soon as it is inoculated. Table 3 summarizes the different results regarding lactic acid, $\mathrm{pH}$, and total acidity of original works that used sequential fermentations between $L$. thermotolerans and Saccharomyces.

Table 3. Summary of sequential combinations between L. thermotolerans and Saccharomyces and their influence on the final lactic acid concentration, $\mathrm{pH}$, and total acidity of the wine. The table reports the increases in lactic acid and total acidity and the reductions in $\mathrm{pH}$ that took place during alcoholic fermentation compared to the initial value of the grape juice before alcoholic fermentation.

\begin{tabular}{cccc}
\hline Study & Lactic Acid (g/L) Increase & Total Acidity (g/L) Increase & pH Decrease \\
\hline Kapsopoulou et al., 2007 [56] & $1.8-5.13$ & $2.04-5.2$ & $0.13-0.3$ \\
Comitini et al., 2011 [57] & n.d.a. & 1.8 & 0.23 \\
Gobbi et al., 2013 [58] & 6.38 & 5.1 & 0.26 \\
Benito et al., 2015 [59] & 1.22 & n.d.a. & 0.12 \\
Benito et al., 2015 [60] & 2.75 & n.d.a. & 0.22 \\
Benito et al., 2016 [61] & 3.18 & n.d.a. & 0.18 \\
Balikci et al., 2016 [62] & n.d.a. & 0.12 \\
Benito et al., 2016 [17] & 2.96 & n.d.a. & 0.21 \\
Benito et al., 2017 [63] & 2.44 & n.d.a. & 0.15 \\
Chen et al., 2018 [64] & 1.7 & 1.2 & 0.11 \\
Dutraive et al., 2019 [53] & 1.51 & n.d.a. & 0.2 \\
Benito et al., 2019 [18] & 1.63 & n.d.a. & 0.17 \\
Morata et al., 2019 [65] & 6.6 & 3.5 & 0.27 \\
Blanco et al., 2020 [47] & 7.1 & 5.7 & 0.3 \\
Romani et al., 2020 [49] & 0.78 & 1.58 & 0.26 \\
Sgouros et al., 2020 [36] & 10.4 & 12.08 & 0.29 \\
Hranilovic et al., 2021 [14] & $1-8.1$ & $0.1-6.1$ & $0.02-0.54$ \\
Snyder et al., 2021 [15] & $0.2-6.1$ & $0-6.2$ & $0-0.33$ \\
\hline
\end{tabular}

n.d.a., no data available.

\subsection{Schizosaccharomyces pombe}

The combination of $L$. thermotolerans with another powerful fermentative yeast, such as $S$. pombe, allows avoiding performing malolactic fermentation in wines with high ethanol concentrations and high $\mathrm{pH}$ levels from warm viticulture areas or overripe grape varieties. In this combination, $L$. thermotolerans increases the acidity, generating lactic acid, while $S$. pombe consumes the unstable malic acid and ends the alcoholic fermentation. The result is a wine stabilized from a malic acid point of view and acidified during alcoholic fermentation. 
Therefore, the wine does not need to undergo malolactic fermentation after alcoholic fermentation.

The studies performed from 2015 to 2018 focused on the effect of this possible combination on basic enological parameters, aroma compounds, and color [19]. This strategy solves the specific problems of modern winemaking, such as a lack of acidity, biogenic amines, ethyl carbamate, or undesirable color losses that take place during classic malolactic fermentation. Color intensities may decrease during lactic acid bacteria malolactic fermentation. On the contrary, the combined use of L. thermotolerans and S. pombe allows maintaining color. The different studies justify the final difference in color because of a lower $\mathrm{pH}$, a direct consequence of the lactic acid produced by L. thermotolerans, which increases the red color intensity and the formation of stable color forms such as vitisins by S. pombe [19].

\subsection{Oenococus oeni}

Some studies have introduced Oenococus oeni into the combinations between L. thermotolerans and the Saccharomyces genus in order to obtain stable wines from a microbiological point of view with a slight increase in the final lactic acid during alcoholic fermentation. This combination may increase the final lactic acid content by approximately $10 \%$ compared to the sequential $L$. thermotolerans control without lactic bacteria [20].

The regular use of this strategy usually comprises an initial co-inoculation between $L$. thermotolerans and O. oeni after $24 \mathrm{~h}$, while S. cerevisiae is inoculated after $48-72 \mathrm{~h}$. Recent studies have shown that some $L$. thermotolerans strains promote malolactic fermentation, while others inhibit it [15]. The presence of lactic acid itself inhibits malolactic fermentation. Levels over $6 \mathrm{~g} / \mathrm{L}$ may completely inhibit malolactic fermentation [15]. These facts justify the recent interest in co-inoculations between L. thermotolerans and O. oeni at the beginning of alcoholic fermentation. However, this new fermentation modality may carry the risk of an increase of acetic acid when O. oeni metabolizes sugars [20]; this risk decreases if the alcoholic fermentation takes place properly, without stopping or becoming sluggish. Recent studies have reported increases in acetic acid compared to co-inoculation and classical sequential inoculation of $O$. oeni, varying from 0.03 to $0.2 \mathrm{~g} / \mathrm{L}[15,20]$. One study reported increases in acetic acid of approximately $50 \%$ for sequential classic malolactic fermentations after a sequential fermentation between $S$. cerevisiae and L. thermotolerans [43].

\subsection{Lactiplantibacillus plantarum (Formerly Lactobacillus plantarum)}

The newest trend introduces combinations of $L$. thermotolerans and other lactic bacteria different from $O$. oeni in order to avoid problems related to the heterofermentative metabolism of this species. Because of that metabolism, O. oeni is mostly inoculated once fermentative yeasts have metabolized all the sugar into ethanol. Lactiplantibacillus plantarum (formerly Lactobacillus plantarum) is an alternative lactic bacteria that possesses a homofermentative metabolism that allows it to be inoculated at the beginning of alcoholic fermentation without risk of sugar consumption. L. plantarum is an interesting option for combining with $L$. thermotolerans in grape juices that suffer from a lack of acidity and contain high initial concentrations of sugar that may originate from extended alcoholic fermentations longer than 21 days [20]. In such situations, L. plantarum metabolizes malic acid during the first stages of alcoholic fermentation, stabilizing the wine from a malic acid point of view. This method reduces the risk of undesirable spoilage microorganisms during difficult long alcoholic fermentation processes, as wine can be protected with sulfur dioxide, lysozyme, or chitosan once malic acid is eliminated. This combination always requires a final inoculation of a high fermentative yeast such as $S$. cerevisiae in order to end the alcoholic fermentation, especially in wines with a high potential ethanol concentration.

This approach reduces, by 18 days, the entire fermentation process and produces wines with improved quality parameters compared to the classical control fermented by classical sequential fermentation by inoculation of $S$. cerevisiae and $O$. oeni when alcoholic fermentation is finished [20]. The final concentration of lactic acid increases by $2.39 \mathrm{~g} / \mathrm{L}$ 
with a $\mathrm{pH}$ reduction of 0.26 compared to the regular control. Other improvements are a slight increase in the glycerol concentration of $0.52 \mathrm{~g} / \mathrm{L}$. Decreases in ethanol and acetic acid have also been reported by approximately $0.37 \%(v / v)$ and $0.08 \mathrm{~g} / \mathrm{L}$, respectively. Regarding aroma compounds, this approach produces wines with higher concentrations of ethyl lactate due to the greater formation of lactic acid and the lower concentrations in diacetyl, as well as a significant increase of 37\% in 2-phenyl ethyl acetate. Another study also reported a decrease in color intensity during the sequential malolactic fermentation by $O$. oen $i$ that did not take place in the combined fermentation between $L$. thermotolerans, $L$. plantarum, and S. bayanus.

\subsection{Other Non-Saccharomyces}

L. thermotolerans may combine with other non-Saccharomyces strains in order to produce wines with different styles, and some researchers have considered the use of popular commercial Saccharomyces strains to increase the risk of producing standardized wines.

The commercial product Melody ${ }^{\mathrm{TM}}$ (Hansen, Horsholm, Denmark) combines L. thermotolerans with Torulaspora delbrueckii and S. cerevisiae [54]. This product started to be commercialized in 2012 and was the first commercial starter that included several nonSaccharomyces yeasts. L. thermotolerans increases the acidity [54], T. delbrueckii increases tropical fruit aromas [66], and S. cerevisiae ensures the alcoholic fermentation is properly ended. One scientific study compared the combined multistarter Melody ${ }^{\mathrm{TM}}$ [21] to a sequential fermentation of the Concerto ${ }^{\mathrm{TM}}$ commercial L. thermotolerans strain with $S$. cerevisiae in Shiraz must. The multistarter showed a higher $\mathrm{pH}$ of 0.06 and 0.08 than the sequential L. thermotolerans control. The competence of L. thermotolerans combined with $T$. delbrueckii and S. cerevisiae explains these differences, as it results in a lower acidification effect than that when fermenting $L$. thermotolerans alone. The multistarter fermentation showed a lower final ethanol concentration of $0.2 \%(v / v)$. One trial reported no differences in acetic acid, while another reported a higher acetic acid production for an L. thermotolerans trial of $0.3 \mathrm{~g} / \mathrm{L}$. The production of acetate esters was reduced by around $21 \%$ in the multistarter fermentation; nevertheless, higher concentrations of 2-phenyl acetate and isoamyl acetate were observed. On the contrary, the concentration of ethyl esters increased by approximately $28 \%$. No differences took place in terms of color intensity, phenolic substances, and non-bleachable pigment. The multistarter showed a lower concentration of anthocyanin by around $10 \%$ and a higher wine hue of 0.06 .

Recently, an inoculum composed of L. thermotolerans and T. delbrueckii in a 30/70 ratio has been proposed [51]. A high implantation capacity characterizes the inoculum, improving wine quality parameters such as the glycerol and lactic acid concentrations significantly. Another proposal is ternary combinations of L. thermotolerans with Metschnikowia pulcherrima or Hanseniaspora vineae and S. cerevisiae [67]. A previous study reported an inhibitory effect of $H$. vineae on acidification, as well as a synergetic effect of $M$. pulcherrima on acidification and ethanol reduction.

Table 4 summarizes the enological impact, advantages, and disadvantages of the reported combinations of $L$. thermotolerans and other microorganisms in winemaking. 
Table 4. Summary of the main L. thermotolerans combinations in winemaking during alcoholic fermentation, explaining their enological impact, advantages, and disadvantages.

\begin{tabular}{|c|c|c|c|}
\hline Combined Species & Enological Impact & Advantages & Disadvantages \\
\hline $\begin{array}{l}\text { Saccharomyces cerevisiae } \\
\text { Benito et al., } 2018 \text { [2] }\end{array}$ & Increase in acidification & $\begin{array}{l}\mathrm{pH} \text { reductions down to } 0.5 \text {; ethanol reduction } \\
\text { down to } 1.6 \%(v / v)\end{array}$ & $\begin{array}{l}\text { Red wines need to perform malolactic } \\
\text { fermentation after alcoholic fermentation }\end{array}$ \\
\hline $\begin{array}{l}\text { Schizosaccharomyces pombe } \\
\text { Benito et al., } 2020 \text { [19] }\end{array}$ & $\begin{array}{l}\text { Increase in acidification by L. thermotolerans; } \\
\text { malic acid stabilization during } \\
\text { alcoholic fermentation by S. pombe }\end{array}$ & $\begin{array}{l}\text { Reduction in production hours; color increase; } \\
\text { ethanol reduction down to } 3 \%(v / v) \text {; biogenic } \\
\text { amines control; ethyl carbamate control }\end{array}$ & $\begin{array}{l}\text { S. pombe strain must be selected to produce } \\
\text { low levels of acetic acid and sulfhidric acid }\end{array}$ \\
\hline $\begin{array}{c}\text { Oenococus oeni } \\
\text { Snyder et al., 2021; Benito et al., } 2021[15,20]\end{array}$ & $\begin{array}{l}\text { Increase in acidification by L. thermotolerans; } \\
\text { malic acid stabilization during } \\
\text { alcoholic fermentation by O. oeni }\end{array}$ & $\begin{array}{l}\text { Reduction in production hours; } \\
\text { increase in color }\end{array}$ & $\begin{array}{c}\text { Risk of an increase in acetic acid; inhibition of } \\
\text { yeast development; biogenic amines } \\
\text { production; ethyl carbamate production }\end{array}$ \\
\hline $\begin{array}{l}\text { Other non-Saccharomyces } \\
\text { Hranilovic et al., 2018; Escribano et al., 2021; } \\
\text { Vaquero et al., } 2021 \text { [21,51,67] }\end{array}$ & Additional value different from acidification & $\begin{array}{l}\text { Aroma complexity; increase in glycerol; } \\
\text { ethanol reduction; synergy }\end{array}$ & $\begin{array}{l}\text { Low fermentative power of most } \\
\text { non-Saccharomyces. }\end{array}$ \\
\hline
\end{tabular}




\section{Grape Varieties, Warm Viticulture Areas, and Climate Change}

The main focus of $L$. thermotolerans application is to improve the lack of acidity, which is one of the key problems affecting vineyards in warm viticulture areas. Other cooler regions could suffer similar problems in the future because of the evolution of climate change. Most studies focus on grape varieties that reach their maturity early. During the maturity process, vine plants synthesize sugar while combusting acids. The first acid to be degraded is malic acid, whose concentration is occasionally very low in very ripened or overripe grapes. In such cases, grapes can reach a $\mathrm{pH}$ of approximately four times the value considered high and may result in sensory and technical problems in winemaking. Mediterranean countries such as Greece [55,56], Italy [57,58], and Spain [60,61] reported the first applications of $L$. thermotolerans, which took place in the big locations of these warm viticultural countries. Climate change is generating problems in new regions that were not considered warm viticulture areas some years ago. The initial studies focused on the most planted national grape varieties from each country. In Italy, varieties such as Pinot Grigio [68] or Sangiovese [49,58] are the most studied alternatives, whereas, in Spain, Tempranillo for red grape plantations $[17,60]$ and Airen [61] for white wine production are the most studied. Tempranillo possesses an early ripening effect (literal translation: "The earliest"), which reduces the potential risks related to long maturation. Airen is a very productive neutral variety whose wine possesses low levels of sugar and low acidity but with a great capacity for development in dry areas. The application of $L$. thermotolerans in Airen wines increases the acidity and esters, improving the acidity balance and fruit aroma, producing more complex wines than the classical neutral Airen [61]. Later studies were performed in Mencia, a red grape variety that presents late budding but early ripening. These properties, characterized by a short development cycle, make it ideal for producing red wine in Atlantic regions with short thermal integrals that were traditionally considered more appropriate to produce white wine. However, because of climate change, this variety has started to show overripening problems in some locations. L. thermotolerans showed interesting improvements when fermenting Mencia [47]. More recent studies have applied $L$. thermotolerans in early international red grape varieties, such as Merlot [14] and Syrah [69]. The other studied varieties are Riesling [53], Muscat of Alexandria [70], and Chardonnay [22] (Table 5). Table 5 clearly shows that most researchers have focused on $L$. thermotolerans applications in grape varieties of early-medium maturity in countries with warm viticulture areas that are more affected by climate change. This shows that other early- or medium-maturity varieties such as Pinot Noir, Malbec, and Tannat could also show positive effects in some regions that could suffer from climate change in the mid-future. Medium-late- or late-maturity varieties such as Carignena, Cabernet Sauvignon, Graciano, Bobal, Monastrel, and Petit Verdot remain to be tested, as overripening problems are less common. However, traditional varieties from cool Atlantic regions such as Treixadura have started to be tested with $L$. thermotolerans to mitigate the future effects of climate change [71]. 
Table 5. Summary of the budding time, ripening time, productivity, and enological potential of grape varieties where Lachancea thermotolerans has been applied.

\begin{tabular}{|c|c|c|c|c|c|}
\hline Study & Grape Variety & Budding Time & Ripening Time & Productivity & Enological Potential \\
\hline Ciani et al., 2006; Binati et al., 2021 [23,68] & Pinot Grigio & Medium-early & Early & Medium-high & $\begin{array}{l}\text { Vinified in white provides a perfumed dry, } \\
\text { alcoholic wine of medium acidity; when } \\
\text { macerated, the body increases }\end{array}$ \\
\hline $\begin{array}{l}\text { Benito et al., 2015; Dutraive et al., } 2019 \\
\text { [53,59] }\end{array}$ & Riesling & Medium & Medium & Medium-low & $\begin{array}{l}\text { Provides aromatic white wines } \\
\text { with greenish reflections }\end{array}$ \\
\hline $\begin{array}{l}\text { Benito et al., 2015, 2016, 2017, 2018, 2019; } \\
\text { Morata et al., } 2019[2,17,18,60,63,65]\end{array}$ & Tempranillo & Medium-early & Medium-early & Medium & $\begin{array}{l}\text { Fruity wines of intense and stable color, high } \\
\text { alcoholic graduation, and medium-low acidity depending on the } \\
\text { degree of ripening }\end{array}$ \\
\hline Beckner Whitener et al., 2015, 2017 [72,73] & Syrah & Medium-late & Medium & Medium & $\begin{array}{l}\text { Produces aromatic ruby red and purple wines, good structure, } \\
\text { alcoholic, complex, and tannic }\end{array}$ \\
\hline $\begin{array}{l}\text { Benito et al., 2016; Vaquero et al., } 2020 \\
\text { [16,61] }\end{array}$ & Airen & Late & Late & High & $\begin{array}{l}\text { Neutral and alcoholic wine of medium-low } \\
\text { quality due to its high productivity; the acidity level is low }\end{array}$ \\
\hline Balikci et al., 2016 [62] & Emir & n.d.a. & n.d.a. & n.d.a. & n.d.a. \\
\hline $\begin{array}{l}\text { Beckner Whitener et al., 2016; Snyder } \\
\qquad 2021[15,74]\end{array}$ & Sauvignon Blanc & Medium-early & Medium & Medium-low & Provides aromatic wines with a thiolic character \\
\hline Shekhawat et al., 2018 [22] & Chardonnay & Early & Early & Medium-high & $\begin{array}{l}\begin{array}{c}\text { Provides wines with varietal flavor, yellow with golden reflections, } \\
\text { and alcoholic }\end{array}\end{array}$ \\
\hline Porter et al., 2019 [70] & $\begin{array}{l}\text { Muscat } \\
\text { of Alexandria }\end{array}$ & Medium-late & Medium-late & Medium & $\begin{array}{l}\text { Provides yellow wines with a golden character and a strong } \\
\text { terpenic aroma }\end{array}$ \\
\hline Castrillo et al., 2019 [71] & Treixadura & Medium-late & Medium & High & $\begin{array}{l}\text { Produces wines of good quality and moderate } \\
\text { alcohol and acidity content in Atlantic regions }\end{array}$ \\
\hline Blanco et al., 2020 [47] & Mencia & Medium-late & Early & Medium-high & $\begin{array}{l}\text { Purple wines with elegant aromas and a good balance of alcohol } \\
\text { and acidity }\end{array}$ \\
\hline Hranilovic et al., 2021 [14] & Merlot & Medium & Medium & Medium-high & $\begin{array}{l}\text { Provides fine fruity wines with an intense ruby red color, alcoholic, } \\
\text { and with a tendency of low acidity }\end{array}$ \\
\hline Escribano-Viana et al., 2021 [51] & Viura & Late & Late & High & $\begin{array}{l}\text { Neutral and alcoholic wine of medium-low } \\
\text { quality due to its high productivity }\end{array}$ \\
\hline Korenika et al., 2021 [44] & $\begin{array}{l}\text { Trnjak, Babic, Blatina, } \\
\text { and Frankovka }\end{array}$ & n.d.a. & n.d.a. & n.d.a. & n.d.a. \\
\hline
\end{tabular}

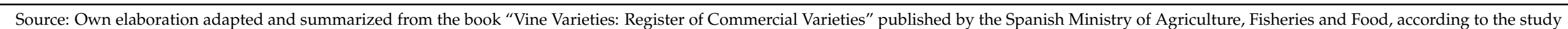

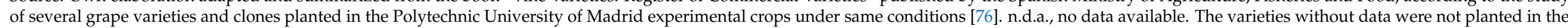
grape variety collection plantation of the Polytechnic University of Madrid. 


\section{Proposed Selection Parameters for L. thermotolerans}

The latest studies that compared commercial strains to other selected strains showed that it is possible to select new strains that perform better than the commercially available ones in several parameters [14,15]. This shows how important it is to establish a proper selection method in order to improve the current commercial offerings and provide solutions to the modern challenges of winemaking.

Former reviews have established the three main $L$. thermotolerans strain selection parameters to be the production of lactic acid up to $9.5 \mathrm{~g} / \mathrm{L}$, acetic acid production down to $0.14 \mathrm{~g} / \mathrm{L}$, and fermentative power up to $10.4 \%(v / v)$ [2]. New studies have suggested updating the previous stabilized levels. According to recent studies, the lactic acid value can increase up to $11.5 \mathrm{~g} / \mathrm{L}$, and the acetic acid concentration can decrease below $0.1 \mathrm{~g} / \mathrm{L}$ [15]. Other recent studies have suggested that with a proper strain selection and controlling the physiochemical conditions, it is possible to ferment up to $13.6 \%(v / v)[6,68]$.

New advances allow the introduction of new selection parameters. Interesting research performed regarding ethanol efficiency production [36] allows reducing the potential content of ethanol by $1 \%$ to $1.6 \%$. This can establish a selection parameter for future studies. L. thermotolerans strains may be selected to reduce the malic acid content down to $50 \%[14,47]$. In red wine technology, this parameter facilitates achieving the desired malic acid microbial stabilization before bottling [19]. However, in white wine production, $L$. thermotolerans strains may be selected to increase the malic acid content by approximately $7 \%$ [6], as most white wines do not require malic acid stabilization and could be of additional interest in highly productive, low acidic white grape varieties such as Airen. The production of glutathione up to the maximum concentration reported in wine for a strain of L. thermotolerans of $24 \mathrm{mg} / \mathrm{L}$ [23] can be established as the selection level. This may protect wine against oxidation and reduce the addition of sulfur dioxide. This can be of great interest in white wine production to protect the color or thiolic character. The highest reported concentration of polysaccharides in a sequential fermentation involving $L$. thermotolerans and S. cerevisiae is $700 \mathrm{mg} / \mathrm{L}$ [49].

Recent studies have shown that sequential fermentations involving $L$. thermotolerans reduce the final concentration of sulfur dioxide. Nowadays, there are consumers that demand wines with low concentrations of sulfur dioxide, such as people who suffer from asthma [50]. Additionally, European legislation is progressively reducing the allowed final concentration [50]. L. thermotolerans management could be an interesting strategy to reduce the final concentration of sulfur dioxide in wine. Additionally, this effect could synergize with the previously mentioned increases in glutathione [23]. The highest reported reduction compared to an S. cerevisiae control is $95 \%$ [14].

L. thermotolerans can be selected to show enzymatic activities that are strain-dependent, such as Lipase, CystineA, or $\beta$-Glucosidase [51]. Depending on the type of wine, these enzymatic activities could be of great interest. $\beta$-glucosidase could improve the final terpene concentration in terpenic varieties, such as Muscat of Alexandria, which has previously been studied in L. thermotolerans applications [70]. Previous studies have described, as an undesirable effect of $L$. thermotolerans, the production of high concentrations of fatty acids such as isovaleric acid, although the selection of $L$. thermotolerans strains without lipase activity may reduce that problem. Other non-Saccharomyces strains such as Metschnikowia or Torulaspora have previously been selected because of cysteine enzymatic activity in order to increase the content of thiols with high success [77]. The strains of $L$. thermotolerans have shown that cysteine enzymatic activity could also improve the content of thiols in thiolic varieties such as Sauvignon Blanc [15] or Riesling [53], which were previously studied in L. thermotolerans applications.

The selection of $L$. thermotolerans strains with pectinase, cellulose, xylanase, and glucanase enzymatic activity is of great interest in the production of wines with higher concentrations of polysaccharides. This could additionally enhance the color or improve the finning processes. The strain variability reported for these enzymatic activities could 
explain the contradictory results regarding the effect of $L$. thermotolerans species on wine and polysaccharide concentration [2].

Some studies have reported some $L$. thermotolerans strains to possess inhibitory effects over lactic bacteria [15]. These results show that compatibility with other microorganisms used in winemaking must be tested for every selected L. thermotolerans strain in order to avoid future problems on the industrial scale.

Although $L$. thermotolerans species possess many virtues, they have a problem when required to produce industrial dehydrated commercial products, as it is very sensitive to this process [78]. A new technology allows evaluating the biophysical stress responses of the L. thermotolerans strains during the dehydration process using synchrotron-FTIR microspectroscopy technology. This factor of dehydration aptitude has to be considered before commercializing a selected strain, as it can influence the cell viability of the final commercial product. Figure 2 summarizes the proposed selected parameters for $L$. thermotolerans.

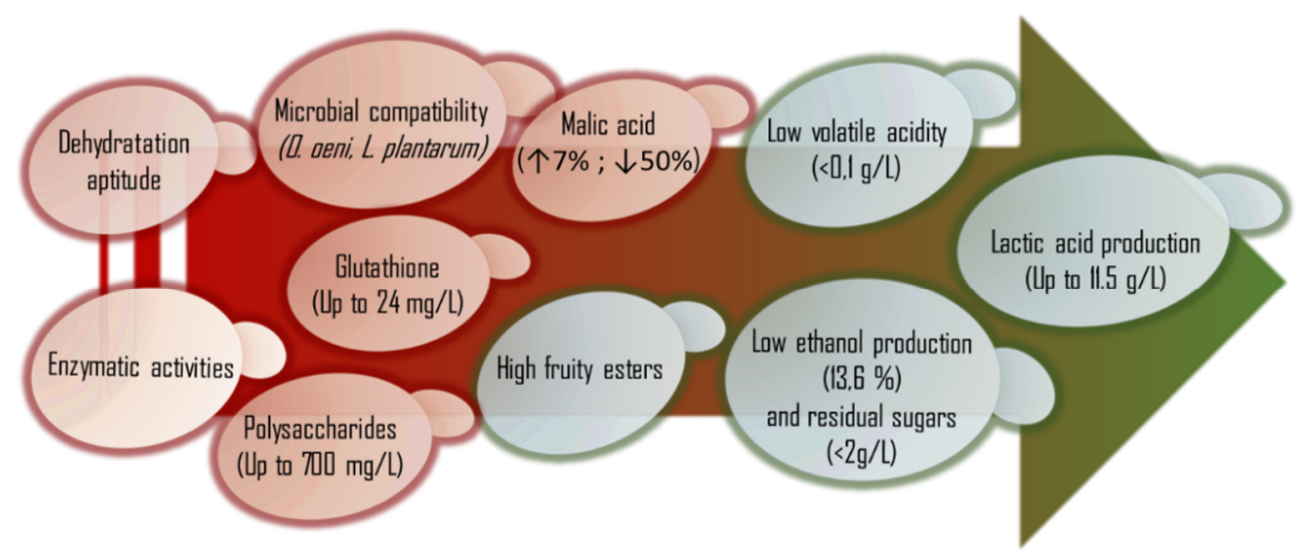

Figure 2. Summary of the proposed Lachancea thermotolerans selection parameters.

\section{Other Lachancea Species}

\subsection{Lachancea fermentati}

L. fermentati shows higher $\mathrm{H}_{2} \mathrm{~S}$ production than L. thermotolerans, varying from $25 \%$ to $50 \%$ higher [70]. L. fermentati showed higher $\mathrm{SO}_{2}$ tolerance and could proliferate at $20 \mathrm{mg} / \mathrm{L}$ of total $\mathrm{SO}_{2}$. L. fermentati could ferment up to $10.5 \%(v / v)$ in a single fermentation, while the $L$. thermotolernas controls fermented up to $10.1 \%(v / v)$. In sequential fermentations between $L$. fermentati or $L$. thermotolerans and S. cerevisiae, L. fermentati produced lower final concentrations in citric acid from $40 \%$ to $50 \%$ and higher final concentrations in acetic acid from $30 \%$ to $60 \%$. Sequential fermentation of $L$. fermetati showed a lower final concentration of total esters of $95 \%$. L. fermetati fermentations did not produce ethyl acetate, while the concentrations of other esters were very low. On the other side, sequential fermentations of $L$. fermentati showed higher final concentrations of total higher alcohols from $18 \%$ to $24 \%$; the major differences took place for isobutanol and isoamyl alcohol. Additionally, sequential fermentations of $L$. fermentati also showed higher final concentrations in total volatile acids from $40 \%$ to $66 \%$; the key differences took place for isobutyric acid.

\subsection{Lachancea lanzarotensis}

Although most studies use L. thermotolerans strains in fermentative studies, one study has tested L. lanzarotensis strains compared to others of L. thermotolerans and L. fermentati in wine fermentation of the Muscat of Alexandria variety [70]. The study only used two strains of L. lanzarotensis in must fermentation, but it is the only available scientific article to date. $L$. lanzarotensis possesses $\beta$-glucosidase enzymatic activity such as $L$. thermotolerans, but not $\beta$-xylosidase [70]. L. lanzarotensis is arbutin-positive but 4-methylumbelliferyl- $\beta$-Dglucoside-negative, while L. thermotolerans is positive for both. 
L. lanzarotensis produces higher $\mathrm{H}_{2} \mathrm{~S}$ levels, from $50 \%$ to $75 \%$, than L. thermotolerans [70]. This study reported lower ethanol tolerance for the L. lanzarotensis strains that fermented wine up to $8.2 \%$ and $8.4 \%(v / v)$ in ethanol, while $L$. thermotolerans fermented up to $10.1 \%$ $(v / v)$ in single fermentations. L. lanzarotensis fermentations in grape juice showed higher final concentrations in citric acid, succinic acid, acetic acid, and glycerol in 40-50\%, 22-33\%, $22-64 \%$, and $20-18 \%$, respectively.

In sequential fermentations between L. lanzarotensis or L. thermotolerans and S. cerevisiae, those of L. lanzarotensis showed a higher final concentration of total esters that varied from $10 \%$ to $22 \%$, and the major differences took place for ethyl acetate. On the other side, sequential fermentations of L. lanzarotensis showed lower final concentrations of total higher alcohols from $9 \%$ to $14 \%$, and the key differences took place for 1-propanol and isoamyl alcohol. Additionally, sequential fermentations of L. lanzarotensis also showed lower final concentrations in total volatile acids from $15 \%$ to $26 \%$, and the fundamental differences took place for propionic and isobutyric acids. The final total terpene concentrations did not show significant differences, although L. lanzarotensis fermentations showed higher contents in citronellol by $22 \%$ to $27 \%$.

\section{Other L. thermotolerans Applications \\ 10.1. Biocontrol and Inhibitory Effects}

Former studies used $L$. thermotolerans as biological agents to protect grapes against fungal attacks [2], although the defense mechanism is not clearly known. A recent study [79] discovered four components of the class of heterocyclic alkaloids, three natural (4-Hydroxyquinoline, Xanthina, and Calistegina A3) and one synthetic (Clausehainanina C) from the crude extract of $L$. thermotolerans. These compounds are antimicrobial, antiproliferative, and inhibitory compounds. They have been tested as biocontrol agents in antagonistic tests of biological tests against phytopathogens that cause fungal and bacterial diseases in agricultural cultures. These results help understand the biocontrol activity of $L$. thermotolerans and the observed inhibitory effects observed in some fermentation studies.

\subsection{Beer}

Previous studies have suggested the application of L. thermotolerans in the beer industry [2] because its high fermentative power is high enough to complete the industrial process in a beverage with a lower ethanol content than wine. The last trends in L. thermotolerans application in beer production propose to select strains with low lactic acid-producing ability in order not to reduce the final $\mathrm{pH}$ of beer [80]. This results in a beer with lower ethanol, maltose, ester, and volatile acid contents, while the glycerol concentration increases.

\section{Conclusions}

Lachancea thermotolerans has already been established as the best bio-acidifier in the wine industry. This ability is of great interest for fighting climate change in modern winemaking. Recent studies have optimized and improved this ability while finding and developing other abilities that can improve the quality of wine. Several recent works have shown that it is possible to select better L. thermotolerans strains than those offered on the market. In addition to the classic selection of established parameters for L. thermotolerans such as lactic acid production, low acetic acid production, and high fermentative power, this review added new ones such as ethanol reduction, glutathione production, sulfur dioxide reduction, malic acid reduction or production, high polysaccharide production, compatibility with other species, color improvement, aroma enhancement, and enzymatic activities of enological interest. Those promising results show that in the future, there could be specific strains of $L$. thermotolerans able to ferment by themselves regular wines of moderate ethanol content and a great number of commercial strains adapted to different types of wine and winemaking objectives. 
New combinations of L. thermotolerans with other yeasts different from Saccharomyces cerevisiae, such as Schizosaccharomyces pombe, and lactic bacteria such as Oenococus oeni or Lactiplantibacillus plantarum allow to produce stable wines from a microbiological point of view in less time just after alcoholic fermentation and to improve some of the quality parameters such as acetic acid, color, or diacetyl content. Combinations with other nonSaccharomyces strains such as Torulaspora delbruecki allow adding additional values to acidification, such as aroma enhancement.

Although the number of studies is limited, species of the Lachancea genus different from $L$. thermotolerans such as L. lanzarotensis or L. fermentati show interesting potential in fermentative industries.

Further studies must be performed regarding fermentation parameters, such as aeration or nitrogen nutrition. Studies that have compared some commercial L. thermotolerans strains between them have shown contradictory results, which show that there are important factors other than the strain parameter.

Despite the studies that have been carried out so far, the ecological role that $L$. thermotolerans plays in the enological ecosystem is still partially unknown. The molecular mechanisms in which the production of lactic acid is involved require further investigation. The regulatory routes and environmental conditions may define the increased activity of certain strains where lactic acid is concerned.

Author Contributions: J.V., E.N., D.M., F.C., A.S. and S.B. contributed to the scientific literature revision, text writing, and editing. J.V. and S.B. oversaw the figure designs. All authors have read and agreed to the published version of the manuscript.

Funding: Funding was provided by the Spanish Center for the Development of Industrial Technology under the framework of Project IDI-20210391 and by the Ministry of Science and Innovation under the framework of Project PID2020-119008RB-I00. Javier Vicente developed this work under a contract (PEJ-2019-AI/BIO-12459) from the Complutense University of Madrid under the framework of the Youth Improvement Initiative (Education and Research Counseling from the Community of Madrid and European Social Fund).

Institutional Review Board Statement: Not applicable.

Informed Consent Statement: Not applicable.

Data Availability Statement: Not applicable.

Conflicts of Interest: The authors declare no conflict of interest.

\section{References}

1. Vicente, J.; Ruiz, J.; Belda, I.; Benito-Vázquez, I.; Marquina, D.; Calderón, F.; Santos, A.; Benito, S. The Genus Metschnikowia in Enology. Microorganisms 2020, 8, 1038. [CrossRef]

2. Benito, S. The impacts of Lachancea thermotolerans yeast strains on winemaking. Appl. Microbiol. Biotechnol. 2018, 102, 6775-6790. [CrossRef] [PubMed]

3. Petruzzi, L.; Capozzi, V.; Berbegal, C.; Corbo, M.R.; Bevilacqua, A.; Spano, G.; Sinigaglia, M. Microbial Resources and Enological Significance: Opportunities and Benefits. Front. Microbiol. 2017, 8, 995. [CrossRef] [PubMed]

4. Vilela, A. Use of Nonconventional Yeasts for Modulating Wine Acidity. Fermentation 2019, 5, 27. [CrossRef]

5. Ferreira, A.M.; Mendes-Faia, A. The Role of Yeasts and Lactic Acid Bacteria on the Metabolism of Organic Acids during Winemaking. Foods 2020, 9, 1231. [CrossRef]

6. Hranilovic, A.; Gambetta, J.M.; Schmidtke, L.; Boss, P.K.; Grbin, P.R.; Masneuf-Pomarede, I.; Bely, M.; Albertin, W.; Jiranek, V. Oenological traits of Lachancea thermotolerans show signs of domestication and allopatric differentiation. Sci. Rep. 2018, 8, 14812. [CrossRef]

7. Vilela, A. Lachancea thermotolerans, the Non-Saccharomyces Yeast that Reduces the Volatile Acidity of Wines. Fermentation 2018, 4 , 56. [CrossRef]

8. Morata, A.; Loira, I.; Tesfaye, W.; Bañuelos, M.A.; González, C.; Lepe, J.A.S. Lachancea thermotolerans Applications in Wine Technology. Fermentation 2018, 4, 53. [CrossRef]

9. Porter, T.J.; Divol, B.; Setati, M.E. Lachancea yeast species: Origin, biochemical characteristics and oenological significance. Food Res. Int. 2019, 119, 378-389. [CrossRef]

10. Domizio, P.; House, J.F.; Joseph, C.M.L.; Bisson, L.F.; Bamforth, C.W. Lachancea thermotolerans as an alternative yeast for the production of beer. J. Inst. Brew. 2016, 122, 599-604. [CrossRef] 
11. Belloch, C.; Barrio, E.; Uruburu, F.; Garcia, M.D.; Querol, A. Characterisation of Four Species of the Genus Kluyveromyces by Mitochondrial DNA Restriction Analysis. Syst. Appl. Microbiol. 1997, 20, 397-408. [CrossRef]

12. Lachance, M.A.; Kurtzman, C.P. Lachancea Kurtzman. Yeasts 2011, 2, 511-519.

13. Vejarano, R.; Gil-Calderón, A. Commercially Available Non-Saccharomyces Yeasts for Winemaking: Current Market, Advantages over Saccharomyces, Biocompatibility, and Safety. Fermentation 2021, 7, 171. [CrossRef]

14. Hranilovic, A.; Albertin, W.; Capone, D.L.; Gallo, A.; Grbin, P.R.; Danner, L.; Bastian, S.E.; Masneuf-Pomarede, I.; Coulon, J.; Bely, M.; et al. Impact of Lachancea thermotolerans on chemical composition and sensory profiles of Merlot wines. Food Chem. 2021, 349, 129015. [CrossRef]

15. Snyder, E.C.; Jiranek, V.; Hranilovic, A. Impact of Lachancea thermotolerans strain and lactic acid concentration on Oenococcus oeni and malolactic fermentation in wine. OENO One 2021, 55, 365-380. [CrossRef]

16. Vaquero, C.; Loira, I.; Bañuelos, M.A.; Heras, J.M.; Cuerda, R.; Morata, A. Industrial Performance of Several Lachancea thermotolerans Strains for $\mathrm{pH}$ Control in White Wines from Warm Areas. Microorganism 2020, 8, 830. [CrossRef]

17. Benito, Á.; Calderón, F.; Benito, S. Combined use of S. pombe and L. thermotolerans in winemaking. Beneficial effects determined through the study of wines' analytical characteristics. Molecules 2016, 21, 1744. [CrossRef]

18. Benito, Á.; Calderón, F.; Benito, S. Mixed alcoholic fermentation of Schizosaccharomyces pombe and Lachancea thermotolerans and its influence on mannose-containing polysaccharides wine Composition. AMB Express 2019, 9, 17. [CrossRef] [PubMed]

19. Benito, S. Combined Use of Lachancea thermotolerans and Schizosaccharomyces pombe in Winemaking: A Review. Microorganisms 2020, 8, 655. [CrossRef]

20. Urbina, Á.; Calderón, F.; Benito, S. The Combined Use of Lachancea thermotolerans and Lactiplantibacillus plantarum (former Lactobacillus plantarum) in Wine Technology. Foods 2021, 10, 1356. [CrossRef]

21. Hranilovic, A.; Li, S.; Boss, P.K.; Bindon, K.; Ristic, R.; Grbin, P.R.; Van der Westhuizen, T.; Jiranek, V. Chemical and sensory profiling of Shiraz wines co-fermented with commercial non-Saccharomyces inocula. Aust. J. Grape Wine Res. 2018, 24, 166-180. [CrossRef]

22. Shekhawat, K.; Porter, T.J.; Bauer, F.F.; Setati, M.E. Employing oxygen pulses to modulate Lachancea thermotolerans-Saccharomyces cerevisiae Chardonnay fermentations. Ann. Microbiol. 2017, 68, 93-102. [CrossRef]

23. Binati, R.; Junior, W.L.; Torriani, S. Contribution of non-Saccharomyces yeasts to increase glutathione concentration in wine. Aust. J. Grape Wine Res. 2021, 27, 290-294. [CrossRef]

24. Kurtzman, C.P.; Robnett, C.J. Phylogenetic relationships among yeasts of the 'Saccharomyces complex' determined from multigene sequence analyses. FEMS Yeast Res. 2003, 3, 417-432. [CrossRef]

25. Friedrich, A.; Jung, P.P.; Hou, J.; Neuvéglise, C.; Schacherer, J. Comparative Mitochondrial Genomics within and among Yeast Species of the Lachancea Genus. PLoS ONE 2012, 7, e47834. [CrossRef]

26. Jean-Luc, S.; Dujon, B.; Gaillardin, C.; Johnston, M.; Baret, P.V.; Cliften, P.; Sherman, D.J.; Weissenbach, J.; Westhof, E.; Wincker, P.; et al. Comparative genomics of protoploid Saccharomycetaceae. Genome Res. 2009, 19, 1696-1709.

27. Payen, C.; Fischer, G.; Marck, C.; Proux, C.; Sherman, D.J.; Coppée, J.-Y.; Johnston, M.; Dujon, B.; Neuvéglise, C. Unusual composition of a yeast chromosome arm is associated with its delayed replication. Genome Res. 2009, 19, 1710-1721. [CrossRef]

28. Gatto, V.; Binati, R.L.; Junior, W.J.L.; Basile, A.; Treu, L.; de Almeida, O.G.; Innocente, G.; Campanaro, S.; Torriani, S. New insights into the variability of lactic acid production in Lachancea thermotolerans at the phenotypic and genomic level. Microbiol. Res. 2020, 238, 126525. [CrossRef]

29. Freel, K.C.; Friedrich, A.; Hou, J.; Schacherer, J. Population genomic analysis reveals highly conserved mitochondrial genomes in the yeast species Lachancea thermotolerans. Genome Biol. Evol. 2014, 6, 2586-2594. [CrossRef]

30. Banilas, G.; Sgouros, G.; Nisiotou, A. Development of microsatellite markers for Lachancea thermotolerans typing and population structure of wine-associated isolates. Microbiol. Res. 2016, 193, 1-10. [CrossRef] [PubMed]

31. Hranilovic, A.; Bely, M.; Masneuf-Pomarede, I.; Jiranek, V.; Albertin, W. The evolution of Lachancea thermotolerans is driven by geographical determination, anthropisation and flux between different ecosystems. PLoS ONE 2017, 12, e0184652. [CrossRef] [PubMed]

32. Dashko, S.; Zhou, N.; Compagno, C.; Piškur, J. Why, when, and how did yeast evolve alcoholic fermentation? FEMS Yeast Res. 2014, 14, 826-832. [CrossRef] [PubMed]

33. Peng, C.; Andersen, B.; Arshid, S.; Larsen, M.R.; Albergaria, H.; Lametsch, R.; Arneborg, N. Proteomics insights into the responses of Saccharomyces cerevisiae during mixed-culture alcoholic fermentation with Lachancea thermotolerans. FEMS Microbiol. Ecol. 2019, 95, 95. [CrossRef] [PubMed]

34. Shekhawat, K.; Patterton, H.; Bauer, F.F.; Setati, M.E. RNA-seq based transcriptional analysis of Saccharomyces cerevisiae and Lachancea thermotolerans in mixed-culture fermentations under anaerobic conditions. BMC Genom. 2019, 20, 145. [CrossRef]

35. Shekhawat, K.; Bauer, F.F.; Setati, M.E. The transcriptomic response of a wine strain of Lachancea thermotolerans to oxygen deprivation. FEMS Yeast Res. 2020, 20, foaa054. [CrossRef]

36. Sgouros, G.; Mallouchos, A.; Filippousi, M.-E.; Banilas, G.; Nisiotou, A. Molecular Characterization and Enological Potential of a High Lactic Acid-Producing Lachancea thermotolerans Vineyard Strain. Foods 2020, 9, 595. [CrossRef] [PubMed]

37. Bertels, L.-K.; Murillo, L.F.; Heinisch, J. The Pentose Phosphate Pathway in Yeasts-More Than a Poor Cousin of Glycolysis. Biomolecules 2021, 11, 725. [CrossRef] 
38. Branduardi, P.; Sauer, M.; De Gioia, L.; Zampella, G.; Valli, M.; Mattanovich, D.; Porro, D. Lactate production yield from engineered yeasts is dependent from the host background, the lactate dehydrogenase source and the lactate export. Microb. Cell Factories 2006, 5, 4. [CrossRef]

39. Sauer, M.; Porro, D.; Mattanovich, D.; Branduardi, P. 16 years research on lactic acid production with yeast-ready for the market? Biotechnol. Genet. Eng. Rev. 2010, 27, 229-256. [CrossRef]

40. Turner, T.; Lane, S.; Jayakody, L.N.; Zhang, G.-C.; Kim, H.; Cho, W.; Jin, Y.-S. Deletion of JEN1 and ADY2 reduces lactic acid yield from an engineered Saccharomyces cerevisiae, in xylose medium, expressing a heterologous lactate dehydrogenase. FEMS Yeast Res. 2019, 19, 19. [CrossRef]

41. Binati, R.L.; Innocente, G.; Gatto, V.; Celebrin, A.; Polo, M.; Felis, G.E.; Torriani, S. Exploring the diversity of a collection of native non-Saccharomyces yeasts to develop co-starter cultures for winemaking. Food Res. Int. 2019, 122, 432-442. [CrossRef] [PubMed]

42. Binati, R.L.; Junior, W.J.L.; Luzzini, G.; Slaghenaufi, D.; Ugliano, M.; Torriani, S. Contribution of non-Saccharomyces yeasts to wine volatile and sensory diversity: A study on Lachancea thermotolerans, Metschnikowia spp. and Starmerella bacillaris strains isolated in Italy. Int. J. Food Microbiol. 2020, 318, 108470. [CrossRef] [PubMed]

43. Zhang, B.; Ivanova-Petropulos, V.; Duan, C.; Yan, G. Distinctive chemical and aromatic composition of red wines produced by Saccharomyces cerevisiae co-fermentation with indigenous and commercial non-Saccharomyces strains. Food Biosci. 2021, 41, 100925. [CrossRef]

44. Korenika, A.-M.J.; Tomaz, I.; Preiner, D.; Lavrić, M.; Šimić, B.; Jeromel, A. Influence of L. thermotolerans and S. cerevisiae Commercial Yeast Sequential Inoculation on Aroma Composition of Red Wines (Cv Trnjak, Babic, Blatina and Frankovka). Fermentation 2021, 7, 4. [CrossRef]

45. Yuhua, W.; Wenjun, S.; Min, L.I.; Lan, M.I.; Yumei, J.; Jing, W. Effect of Sequential Fermentation with Lachancea thermotolerans and Schizosaccharomyces pombe on the Quality of Merlot Dry Red Wine. Food Sci. 2019, 40, 102-111.

46. Escribano, R.; González-Arenzana, L.; Portu, J.; Garijo, P.; López-Alfaro, I.; López, R.; Santamaría, P.; Gutiérrez, A. Wine aromatic compound production and fermentative behaviour within different non-Saccharomyces species and clones. J. Appl. Microbiol. 2018, 124, 1521-1531. [CrossRef]

47. Blanco, P.; Rabuñal, E.; Neira, N.; Castrillo, D. Dynamic of Lachancea thermotolerans Population in Monoculture and Mixed Fermentations: Impact on Wine Characteristics. Beverages 2020, 6, 36. [CrossRef]

48. Benito, S. The impacts of Schizosaccharomyces on winemaking. Appl. Microbiol. Biotechnol. 2019, 103, 4291-4312. [CrossRef]

49. Romani, C.; Lencioni, L.; Bartolini, A.B.; Ciani, M.; Mannazzu, I.; Domizio, P. Pilot Scale Fermentations of Sangiovese: An Overview on the Impact of Saccharomyces and Non-Saccharomyces Wine Yeasts. Fermentation 2020, 6, 63. [CrossRef]

50. Benito, S. The Management of Compounds that Influence Human Health in Modern Winemaking from an HACCP Point of View. Fermentation 2019, 5, 33. [CrossRef]

51. Escribano-Viana, R.; González-Arenzana, L.; Garijo, P.; López, R.; Santamaría, P.; Gutiérrez, A.R. Selection Process of a Mixed Inoculum of Non-Saccharomyces Yeasts Isolated in the D.O.Ca. Rioja. Fermentation 2021, 7, 148. [CrossRef]

52. Belda, I.; Ruiz, J.; Alastruey-Izquierdo, A.; Navascués, E.; Marquina, D.; Santos, A. Unraveling the enzymatic basis of wine "Flavorome": A phylo-functional study of wine related yeast species. Front. Microbiol. 2016, 7, 12. [CrossRef] [PubMed]

53. Dutraive, O.; Benito, S.; Fritsch, S.; Beisert, B.; Patz, C.-D.; Rauhut, D. Effect of Sequential Inoculation with Non-Saccharomyces and Saccharomyces Yeasts on Riesling Wine Chemical Composition. Fermentation 2019, 5, 79. [CrossRef]

54. Roudil, L.; Russo, P.; Berbegal, C.; Albertin, W.; Spano, G.; Capozzi, V. Non-Saccharomyces Commercial Starter Cultures: Scientific Trends, Recent Patents and Innovation in the Wine Sector. Recent Pat. Food Nutr. Agric. 2020, 11, 27-39. [CrossRef]

55. Kapsopoulou, K.; Kapaklis, A.; Spyropoulos, H. Growth and Fermentation Characteristics of a Strain of the Wine Yeast Kluyveromyces thermotolerans Isolated in Greece. World J. Microbiol. Biotechnol. 2005, 21, 1599-1602. [CrossRef]

56. Kapsopoulou, K.; Mourtzini, A.; Anthoulas, M.; Nerantzis, E. Biological acidification during grape must fermentation using mixed cultures of Kluyveromyces thermotolerans and Saccharomyces cerevisiae. World J. Microbiol. Biotechnol. 2006, 23, 735-739. [CrossRef]

57. Comitini, F.; Gobbi, M.; Domizio, P.; Romani, C.; Lencioni, L.; Mannazzu, I.; Ciani, M. Selected non-Saccharomyces wine yeasts in controlled multistarter fermentations with Saccharomyces cerevisiae. Food Microbiol. 2011, 28, 873-882. [CrossRef]

58. Gobbi, M.; Comitini, F.; Domizio, P.; Romani, C.; Lencioni, L.; Mannazzu, I.; Ciani, M. Lachancea thermotolerans and Saccharomyces cerevisiae in simultaneous and sequential co-fermentation: A strategy to enhance acidity and improve the overall quality of wine. Food Microbiol. 2013, 33, 271-281. [CrossRef] [PubMed]

59. Benito, S.; Hofmann, T.; Laier, M.; Lochbühler, B.; Schüttler, A.; Ebert, K.; Fritsch, S.; Röcker, J.; Rauhut, D. Effect on quality and composition of Riesling wines fermented by sequential inoculation with non-Saccharomyces and Saccharomyces cerevisiae. Eur. Food Res. Technol. 2015, 241, 707-717. [CrossRef]

60. Benito, Á.; Calderón, F.; Palomero, F.; Benito, S. Combine Use of Selected Schizosaccharomyces pombe and Lachancea thermotolerans Yeast Strains as an Alternative to theTraditional Malolactic Fermentation in Red Wine Production. Molecules 2015, 20, 9510-9523. [CrossRef] [PubMed]

61. Benito, Á.; Calderón, F.; Palomero, F.; Benito, S. Quality and Composition of Airén Wines Fermented by Sequential Inoculation of Lachancea thermotolerans and Saccharomyces cerevisiae. Food Technol. Biotechnol. 2016, 54, 135-144. [CrossRef]

62. Balikci, E.K.; Tanguler, H.; Jolly, N.P.; Erten, H. Influence of Lachancea thermotolerans on cv. Emir wine fermentation. Yeast 2016, 33, 313-321. [CrossRef] 
63. Benito, Á.; Calderón, F.; Benito, S. The Combined Use of Schizosaccharomyces pombe and Lachancea thermotolerans-Effect on the Anthocyanin Wine Composition. Molecules 2017, 22, 739. [CrossRef]

64. Chen, K.; Escott, C.; Loira, I.; del Fresno, J.M.; Morata, A.; Tesfaye, W.; Calderon, F.; Suárez-Lepe, J.A.; Han, S.; Benito, S. Use of non- Saccharomyces yeasts and oenological tannin in red winemaking: Influence on colour, aroma and sensorial properties of young wines. Food Microbiol. 2018, 69, 51-63. [CrossRef] [PubMed]

65. Morata, A.; Bañuelos, M.A.; Vaquero, C.; Loira, I.; Cuerda, R.; Palomero, F.; González, C.; Suárez-Lepe, J.A.; Wang, J.; Han, S.; et al. Lachancea thermotolerans as a tool to improve $\mathrm{pH}$ in red wines from warm regions. Eur. Food Res. Technol. 2019, 245, 885-894. [CrossRef]

66. Belda, I.; Ruiz, J.; Beisert, B.; Navascués, E.; Marquina, D.; Calderón, F.; Rauhut, D.; Benito, S.; Santos, A. Influence of Torulaspora delbrueckii in varietal thiol (3-SH and 4-MSP) release in wine sequential fermentations. Int. J. Food Microbiol. 2017, 257, 183-191. [CrossRef]

67. Vaquero, C.; Loira, I.; Heras, J.M.; Carrau, F.; González, C.; Morata, A. Biocompatibility in Ternary Fermentations with Lachancea thermotolerans, Other Non-Saccharomyces and Saccharomyces cerevisiae to Control pH and Improve the Sensory Profile of Wines From Warm Areas. Front. Microbiol. 2021, 12, 832. [CrossRef] [PubMed]

68. Ciani, M.; Beco, L.; Comitini, F. Fermentation behaviour and metabolic interactions of multistarter wine yeast fermentations. Int. J. Food Microbiol. 2006, 108, 239-245. [CrossRef]

69. Du Plessis, H.; Du Toit, M.; Hoff, J.; Hart, R.; Ndimba, B.; Jolly, N. Characterisation of Non-Saccharomyces Yeasts Using Different Methodologies and Evaluation of their Compatibility with Malolactic Fermentation. South Afr. J. Enol. Vitic. 2017, 38, 46-63. [CrossRef]

70. Porter, T.J.; Divol, B.; Setati, M.E. Investigating the biochemical and fermentation attributes of Lachancea species and strains: Deciphering the potential contribution to wine chemical composition. Int. J. Food Microbiol. 2019, 290, 273-287. [CrossRef]

71. Castrillo, D.; Rabuñal, E.; Neira, N.; Blanco, P. Oenological potential of non-Saccharomyces yeasts to mitigate effects of climate change in winemaking: Impact on aroma and sensory profiles of Treixadura wines. FEMS Yeast Res. 2019, 19, foz065. [CrossRef] [PubMed]

72. Whitener, M.B.; Carlin, S.; Jacobson, D.; Weighill, D.; Divol, B.; Conterno, L.; Du Toit, M.; Vrhovsek, U. Early fermentation volatile metabolite profile of non-Saccharomyces yeasts in red and white grape must: A targeted approach. LWT 2015, 64, 412-422 [CrossRef]

73. Whitener, M.B.; Stanstrup, J.; Carlin, S.; Divol, B.; Du Toit, M.; Vrhovsek, U. Effect of non-Saccharomyces yeasts on the volatile chemical profile of Shiraz wine. Aust. J. Grape Wine Res. 2017, 23, 179-192. [CrossRef]

74. Whitener, B.M.E.; Stanstrup, J.; Panzeri, V.; Carlin, S.; Divol, B.; Du Toit, M.; Vrhovsek, U. Untangling the wine metabolome by combining untargeted SPME-GCxGC-TOF-MS and sensory analysis to profile Sauvignon blanc co-fermented with seven different yeasts. Metabolomics 2016, 12, 53. [CrossRef]

75. Viana, R.E.; González-Arenzana, L.; Portu, J.; Garijo, P.; López-Alfaro, I.; López, R.; Santamaría, P.; Gutiérrez, A.R. Wine aroma evolution throughout alcoholic fermentation sequentially inoculated with non-Saccharomyces/Saccharomyces yeasts. Food Res. Int. 2018, 112, 17-24. [CrossRef]

76. Chomé Fuster, P.M. Variedades de Vid: Registro de Variedades Comerciales; Ministerio de Agricultura, Pesca y Alimentación: Madrid, Spain, 2006.

77. Ruiz, J.; Kiene, F.; Belda, I.; Fracassetti, D.; Marquina, D.; Navascués, E.; Calderón, F.; Benito, A.; Rauhut, D.; Santos, A.; et al. Effects on varietal aromas during wine making: A review of the impact of varietal aromas on the flavor of wine. Appl. Microbiol. Biotechnol. 2019, 103, 7425-7450. [CrossRef] [PubMed]

78. Câmara, A.A.J.; Nguyen, T.D.; Saurel, R.; Sandt, C.; Peltier, C.; Dujourdy, L.; Husson, F. Biophysical Stress Responses of the Yeast Lachancea thermotolerans During Dehydration Using Synchrotron-FTIR Microspectroscopy. Front. Microbiol. 2020, 11, 899. [CrossRef]

79. Torres, M.; Ribeiro, M.A.S.; Oliveira, J.A.S.; Meurer, E.C.; Schwan-Estrada, K.R.F. Partial chemical characterization of the yeast extracts Lachancea thermotolerans. CCMA Afr. J. Microbiol. Res. 2021, 15, 388-395.

80. Zdaniewicz, M.; Satora, P.; Pater, A.; Bogacz, S. Low Lactic Acid-Producing Strain of Lachancea thermotolerans as a New Starter for Beer Production. Biomolecules 2020, 10, 256. [CrossRef] 